\title{
IAC-05-C3.4-D2.8.04
}

\section{High-Voltage Array Ground Test for Direct-Drive Solar Electric Propulsion}

\author{
Joe T. Howell \\ NASA Marshall Space Flight Center \\ Advanced Projects Team, SP20 \\ Huntsville, AL 35812 USA \\ E-mail: Joe.Howell@nasa.gov \\ Tel: 256-961-7566 \\ Fax: 256-961-7149 \\ John C. Mankins \\ Artemis Innovation Management Solutions, LLC \\ Ashburn, VA 20147 USA \\ E-mail: john.c.mankins@artemisinnovation.com
}

Mark J. O'Neill

ENTECH, Inc.

1077 Chisolm Trail

Keller, TX 76248 USA

E-mail: mjoneill@entechsolar.com

Tel: $817-379-0100$

Fax: 817-379-0300

\begin{abstract}
Development is underway on a unique high-power solar concentrator array called Stretched Lens Array (SLA) for direct drive electric propulsion. These SLA performance attributes closely match the critical needs of solar electric propulsion (SEP) systems, which may be used for "space tugs" to fuel-efficiently transport cargo from low earth orbit (LEO) to low lunar orbit (LLO), in support of NASA's robotic and human exploration missions. Later SEP systems may similarly transport cargo from the earth-moon neighborhood to the Mars neighborhood.

This paper will describe the SLA SEP technology, discuss ground tests already completed, and present plans for future ground tests and future flight tests of SLA SEP systems.
\end{abstract}




\section{INTRODUCTION}

ENTECH and other organizations have developed a new space photovoltaic array called the Stretched Lens Array (SLA), which offers unprecedented performance (e.g., $>80 \mathrm{~kW} / \mathrm{m}^{3}$ stowed power, $>300 \mathrm{~W} / \mathrm{m}^{2}$ areal power, and $>300 \mathrm{~W} / \mathrm{kg}$ specific power in the very near term) and cost-effectiveness (>75\% savings in \$/W compared to planar highefficiency arrays). SLA achieves these outstanding attributes by employing flexible Fresnel lenses for optical concentration, thereby minimizing solar cell area, mass, and cost. SLA's small cell size (less cell area than planar high-efficiency arrays) also allows super-insulation and super-shielding of the solar cells to enable high-voltage operation and radiation hardness in the space environment. Recent studies show that SLA offers a 3-4X advantage over competing arrays in specific power for many NASA Exploration missions. ENTECH is working at different levels to develop and demonstrate special versions of SLAs, specifically to be optimized for Solar Electric Propulsion (SEP) missions. The SLAs for SEP will operate at $600 \mathrm{~V}$ to direct-drive an electric thrusters. Such a combination of ultra-light, high-voltage, radiation-hard SLAs with a highspecific-impulse electric thrusters will have widespread applicability to many NASA, DOD, and commercial missions.

SLA is a unique ultra-high-performance, ultra-light, cost-effective photovoltaic concentrator array, which is described in more detail in a following section. SLA is an evolutionary development based on the successful SCARLET array flown on Deep Space 1, which itself was based on the Mini-Dome Lens array flown on PASP-Plus. These earlier arrays are briefly discussed in a following section. The various ongoing activities focus on design, development and experimental validation of special versions of SLAs, specifically optimized for direct-driving electric thrusters. Direct-driving of an electric thruster is an innovative technique pioneered by NASA to minimize the inefficiency, mass, cost, and complexity of the power distribution system (PDS) that interface the solar arrays and electric thrusters. The mass savings and other advantages offered by directdriving electric thrusters have been documented for various space missions by Aerojet, NASA Glenn, NASA Marshall, and SAIC [1 and 2]. Direct-driving requires the solar array to operate at the voltage level needed to drive the electric thruster. The various ongoing activities are focusing on SLAs that can be developed and demonstrated to operate reliably at $600 \mathrm{~V}$, to meet both the near term and longer term needs for direct-driving electric thrusters.

The upper limit in operating voltage for present space solar arrays is about $100 \mathrm{~V}$, excluding only the unique $160 \mathrm{~V}$ array on the International Space Station (ISS). Even some $100 \mathrm{~V}$ arrays have had serious discharge, arcing, and ground-fault problems on orbit, indicating the challenge of moving the array operating voltage to $600 \mathrm{~V}$ under the proposed program [3 and 4].

Fig. 1 shows the conceptual design of the proposed $600 \mathrm{~V}$ SLA for SEP innovation in an important nearterm NASA lunar exploration mission.

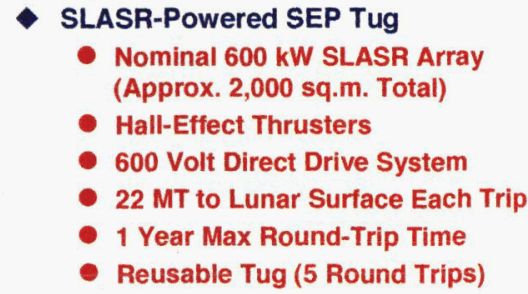

- Reusable Lunar Tug Mission

- Five Round-Trips (One per Year) from LEO $(400 \mathrm{~km})$ to LLO, with On-Board Chemically Fueled Lander Delivering Cargo to Lunar Surface

- First LEO Launch Contains Tug, Xenon, Lander with Chemical Fuel, and Cargo

- Subsequent LEO Launches Provide New Xenon, Lander with Fuel, and Cargo, Which Dock with Tug in LEO for Next Trip

- 28 Degree Inclination Near Earth with Plane Changes Near Moon
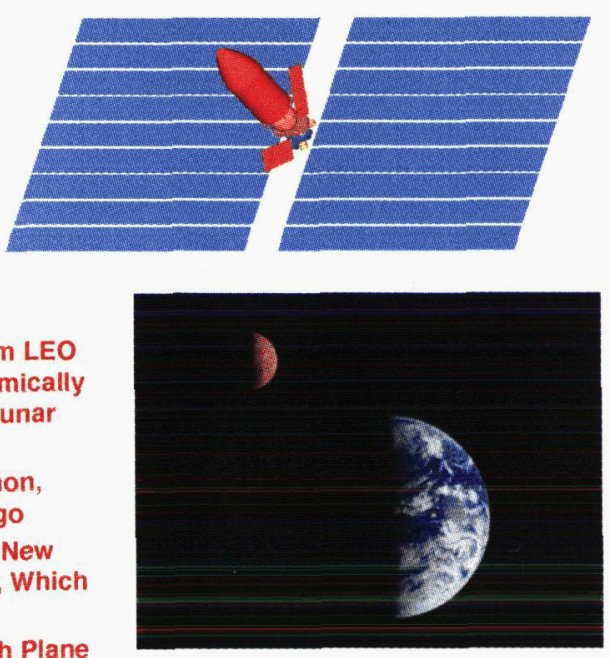

Fig. 1. SLA for SEP in a Lunar Cargo Tug Application. 
To support robotic and human missions to the moon in the next decade, large quantities of cargo will need to be delivered to the lunar surface. Rather than using conventional chemical propulsion cargo transports, a reusable SEP tug could do the same job for billions of dollars less cost. The SEP tug described in Fig. 1 uses SLA on a high-power, ultralight platform known as SquareRigger (SR), developed by Able Engineering (now ATK Space), and described in more detail in a following section. SLA on SquareRigger has the acronym, SLASR.

A nominal $600 \mathrm{~kW}$ SLASR will have an area of about $2,000 \mathrm{~m}^{2}$, and will be capable of a round-trip from low earth orbit (LEO) to low lunar orbit (LLO) in less than a year, delivering 22 MT of cargo to the lunar surface. The SEP mission summarized in Fig. 1 is relatively simple, but very demanding on the solar array, which must survive ten slow spiraling transits through the Earth's radiation belts. Even for today's advanced triple-junction solar cells, the radiation dose for this mission requires significant radiation shielding of the cells to keep power degradation in a reasonable range. Furthermore, the array must operate at $600 \mathrm{~V}$ continuously and reliably for five years, in a variety of space environments, varying from LEO to lunar orbit. To make this SEP tug mission practical, the array must also be very efficient, to minimize area and drag in LEO, extremely light-weight, to minimize parasitic mass, manufacturable at high rates, to allow a $600 \mathrm{~kW}$ array to be made in a reasonable time, and cost-effective, to make a $600 \mathrm{~kW}$ array affordable. Fortunately, the proposed SLA for SEP array meets all of these requirements, as further discussed in a following section.
Fig. 2 summarizes the spectacular economic payoff of the proposed SLASR-powered SEP space tug shown in Fig. 1. The results summarized in Fig. 2 were generated based on a set of analyses, including trajectory analysis, radiation environment analysis, cell shielding and degradation analysis, and vehicle mass estimates. Over its five year lifetime, one reusable SLASR-powered SEP tug will provide over $\$ 3$ Billion in savings in launch costs alone, compared to conventional chemical propulsion delivery of the same 110 MT of cargo to the lunar surface. In addition one reusable SLASR-powered SEP tug will replace five conventional chemical propulsion LEOto-LLO cargo delivery spacecraft for an additional savings of perhaps another $\$ 1$ Billion. Cost estimates of one SLASR-powered SEP tug as shown in Fig. 1 amount to approximately $10 \%$ of the total savings shown in Fig. 2. Thus, the significance of the SLASR-powered SEP innovation is substantial in terms of direct cost savings to NASA in near-term lunar exploration missions. Clearly, the same technology will be applicable to later cargo missions to Mars and beyond, with similar spectacular payoffs. Many additional non-NASA applications for the proposed SLA for SEP technology also exist, from LEO to GEO orbit raising for commercial communication satellites to repositioning of DOD space assets to meet specific mission requirements. To achieve the payoff outlined in Fig. 2, development and demonstration of $600 \mathrm{~V}$ SLAs for SEP directdriving of electric thrusters are needed. Several NASA-sponsored programs are underway to advance SLA technology and SEP technology, and to perform ground testing of thrusters under direct drive from high-voltage solar arrays. However, these programs are in early stages, with current activities advancing

\begin{tabular}{|c|c|c|c|}
\hline \multicolumn{2}{|c|}{ Conventional Chemical Cargo Transport } & \multicolumn{2}{|c|}{ Reusable SLA-Powered SEP Cargo Transport } \\
\hline Item & Mass & Item & Mass \\
\hline LEO-to-LLO Vehicle (Expendable) & $10 \mathrm{MT}$ & LEO-to-LLO Vehicle (Reusable) & $10 \mathrm{MT}$ \\
\hline Cargo (Including Lander) & $22 \mathrm{MT}$ & Cargo (Including Lander) & $22 \mathrm{MT}$ \\
\hline LLO-to-Lunar Surface Fuel & $15 \mathrm{MT}$ & LLO-to-Lunar Surface Fuel & $15 \mathrm{MT}$ \\
\hline LEO-to-LLO Fuel & $80 \mathrm{MT}$ & LEO-to-LLO Propellant (Xenon) & $23 \mathrm{MT}$ \\
\hline Total Launch Mass & $127 \mathrm{MT}$ & Total Launch Mass (First Launch wNehicle) & $70 \mathrm{MT}$ \\
\hline & & Total Launch Mass (Subsequent Launches) & $60 \mathrm{MT}$ \\
\hline $\begin{array}{l}\text { Total LEO Launch Mass for Five Deliveries } \\
\text { Over Five Years ( } 110 \text { MT Total Cargo) }\end{array}$ & 635 MT & $\begin{array}{l}\text { Total LEO Launch Mass for Five Deliveries } \\
\text { Over Five Years (110 MT Total Cargo) } \\
\end{array}$ & $310 \mathrm{MT}$ \\
\hline Launch Costs Using Shuttle-Derived Heavy & $\$ 6,350$ Million & Launch Costs Using Shuttle-Derived Heavy & $\$ 3,100$ Million \\
\hline (\$10 MMT from ATK: safesimplesoon.com) & & (\$10 M/MT from ATK: safesimplesoon.com) & \\
\hline
\end{tabular}

- SEP Offers Over \$3 Billion in Savings Just in Launch Costs per Tug

- SEP Offers Additional Savings of 4 Fewer LEO-to-LLO Vehicles

- More than 5 Round-Trips May Be Practical for SEP Tug (More Savings)

- For 70-MT-Class Shuttle-Derived Launch Vehicles, SEP Approach Will

Require Half as Many Launches as Chemical Approach, and, as ATK

Accurately States, "Fewer Launches + Fewer Payloads + Fewer In-

Space Assemblies = Higher Mission Reliability"

Fig. 2. Spectacular Payoff: SLASR-Powered SEP Lunar Cargo Tug Application. 
various aspects of the technology, i.e., modeling, component testing, planning and road mapping for future activities, etc.

The following sections provide additional details on the proposed SLA for SEP technology.

\section{BACKGROUND}

Since 1986, ENTECH and NASA have been developing and refining space photovoltaic arrays using refractive concentrator technology [5]. Unlike reflective concentrators, these refractive Fresnel lens concentrators can be configured to minimize the effects of shape errors, enabling straightforward manufacture, assembly, and operation on orbit. By using a unique arch shape, these Fresnel lenses provide more than $100 \mathrm{X}$ larger slope error tolerance than either reflective concentrators or conventional flat Fresnel lens concentrators [6].

In the early 1990 's, the first refractive concentrator array was developed and flown on the PASP Plus mission, which included a number of small advanced arrays [7]. The refractive concentrator array used ENTECH mini-dome lenses over Boeing mechanically stacked multi-junction (MJ) cells ( $\mathrm{GaAs}$ over $\mathrm{GaSb}$ ). The mini-dome lenses were made by ENTECH from space-qualified silicone (DC 93-500), and coated by Boeing and OCLI to provide protection against space ultraviolet (UV) radiation and atomic oxygen (AO). Fig. 3 shows the minidome lens array which flew on PASP Plus. This array performed extremely well throughout the yearlong mission in a high-radiation, 70-degree inclination, $363 \mathrm{~km}$ by $2,550 \mathrm{~km}$ elliptical orbit, validating both the high performance and radiation hardness of the refractive concentrator approach [7]. Indeed, the mini-dome lens array provided the highest performance and the lowest degradation of all

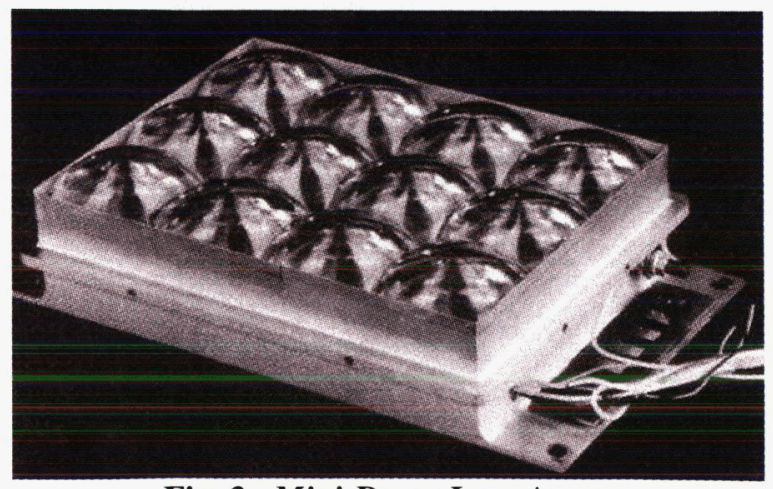

Fig. 3. Mini-Dome Lens Array for PASP Plus (1994-1995).
12 advanced arrays on the PASP Plus flight test [7]. In addition, in high-voltage space plasma interaction experiments, the refractive concentrator array was able to withstand cell voltage excursions to $500 \mathrm{~V}$ relative to the plasma with minimal environmental interaction [7].

In the middle 1990's, ENTECH and NASA developed a new line-focus Fresnel lens concentrator, which is easier to make and more cost-effective than the mini-dome lens concentrator. Using a continuous roll-to-roll process, $3 \mathrm{M}$ can now rapidly massproduce the line-focus silicone lens material in any desired quantity.

In 1994, ABLE joined the refractive concentrator team and led the development of the SCARLET ${ }^{\circledR}$ (Solar Concentrator Array using Refractive Linear Element Technology) solar array [8 and 9]. SCARLET used a small $(8.5 \mathrm{~cm}$ wide aperture) silicone Fresnel lens to focus sunlight at $8 \mathrm{X}$ concentration onto radiatively cooled triple-junction cells. Launched in October 1998, a 2.5 kW SCARLET array powered both the spacecraft and the ion engine on the NASA/JPL Deep Space 1 probe, shown in Fig. 4. SCARLET achieved over $200 \mathrm{~W} / \mathrm{m}^{2}$ areal power density and over $45 \mathrm{~W} / \mathrm{kg}$ specific power, the best performance metrics up to that time [8 and 9]. The SCARLET array was the first solar array to fly using triple junction solar cells as the principal power source for a spacecraft. With SCARLET working flawlessly, Deep Space 1 had a spectacularly successful rendezvous with the comet, Borrelly, in September 2001, capturing the highestresolution images of a comet to that date and other unprecedented comet data. At the end of the 38month extended mission, in December 2001, SCARLET's power was still within $\pm 2 \%$ of predictions. The SCARLET array won the Schreiber-

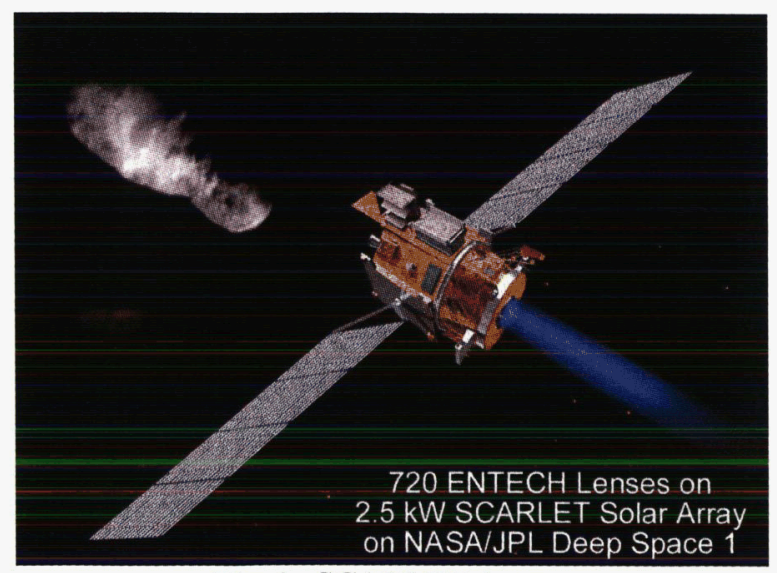

Fig 4. SCARLET Array on Deep Space 1 (1998-2001). 
Spence Technology Achievement Award in 1999 and the NASA Turning Goals into Reality (TGIR) Award in 2001 .

Over the past six years, the team, now including Auburn University, EMCORE, and Ion Beam Optics, has developed an ultra-light version of the flightproven SCARLET array, called the Stretched Lens Array (SLA), with much better performance metrics, as described in the following paragraphs [10].

The Stretched Lens Array (SLA) is an evolved version of SCARLET, retaining the essential powergenerating elements (the silicone Fresnel lens, the multi-junction solar cells, and the composite radiator sheet) while discarding many of the non-powergenerating elements (the lens glass arch superstrates, the lens support frames, the photovoltaic receiver support bars, and most of the honeycomb and back face sheet material in the panels). Fig. 5 shows the near-term, low-risk, rigid-panel version of SLA.

The defining feature of SLA that enables the elimination of so many elements of the SCARLET array is the stretched lens optical concentrator (Fig. 6). By using pop-up arches to stretch the silicone Fresnel lens in the lengthwise direction only, these lenses become self-supporting stressed membranes. SCARLET's glass arches are thus no longer needed, eliminating their complexity, fragility, expense, and mass in the new, patented SLA [11]. With this substantial lens-related mass reduction, the supporting panel structural loads are reduced, making ultra-light panels practical for SLA. This cascading mass-reducing effect of the stretched lenses continues throughout the SLA wing structure, resulting in unprecedented performance metrics. Because of its $8.5 \mathrm{X}$ geometric concentration ratio, SLA saves over $85 \%$ of the required area, mass and cost of the multijunction solar cells per Watt of power produced. Significantly, the total combined areal mass density ( $\mathrm{kg}$ per $\mathrm{m}^{2}$ of sun-collecting aperture area) of the lens material, the radiator sheet material, and the fully assembled photovoltaic receiver is much less (about $50 \%$ ) than for a one-sun multi-junction cell assembly alone (unmounted). Thus, SLA has a substantial inherent mass advantage over planar, one-sun multijunction-cell solar arrays. Similarly, due to its $85 \%$ cell area and cost savings, SLA has a substantial inherent power cost advantage $(\$ / W)$ over such planar multi-junction-cell arrays.

All three refractive concentrator arrays discussed above, the mini-dome lens, SCARLET, and SLA, use Fresnel lens optical elements based on the same

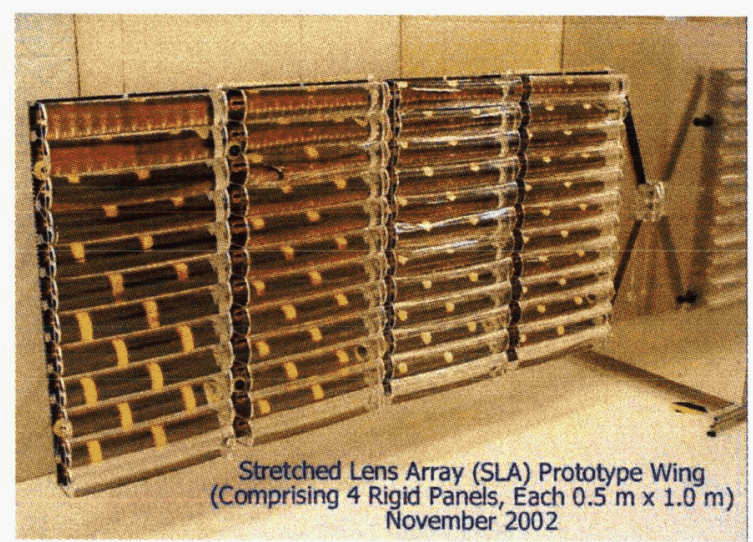

Fig. 5. Rigid-Panel Stretched Lens Array (SLA) Wing.

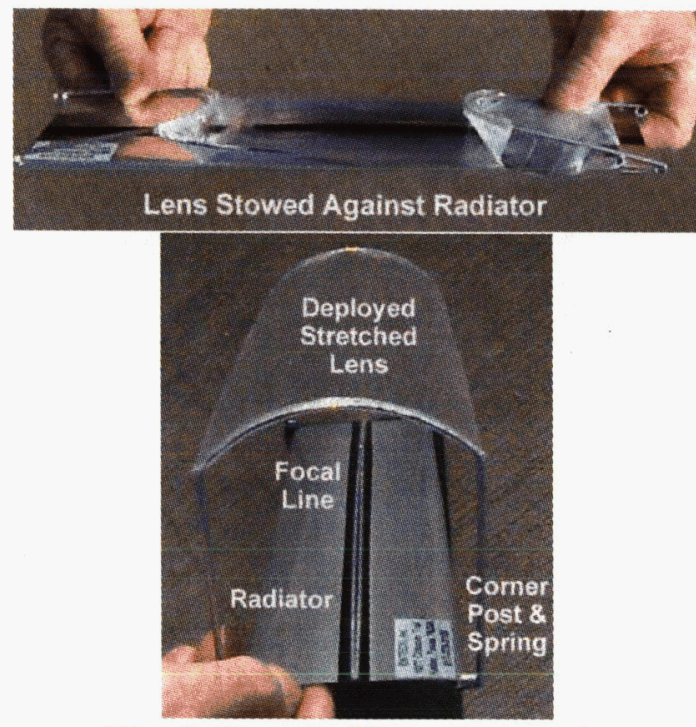

Fig. 6. Stretched Lens Approach.

symmetrical refraction principle, shown schematically in Fig. 7. Solar rays intercept the smooth convex outer lens surface and are each refracted by the curved outer surface by one half the angular amount needed to focus these rays onto the solar cell. The other half of the required refraction is performed as the rays leave the inner prismatic lens surface. Thus, the solar ray incidence angle at the smooth outer surface equals the solar ray emergence angle at the prismatic inner surface for every ray, as shown in the enlarged view of the lens in Fig. 7. This symmetrical refraction (angle in = angle out) condition minimizes reflection losses at the two lens surfaces, thereby providing maximal optical performance, while also offering unprecedented error tolerance for the mini-dome, SCARLET, and SLA lenses [6]. The mini-dome lens array uses a pointfocus (3D) version of the symmetrical refraction lens, while both SCARLET and SLA use a line-focus (2D) version of the symmetrical refraction lens. The 


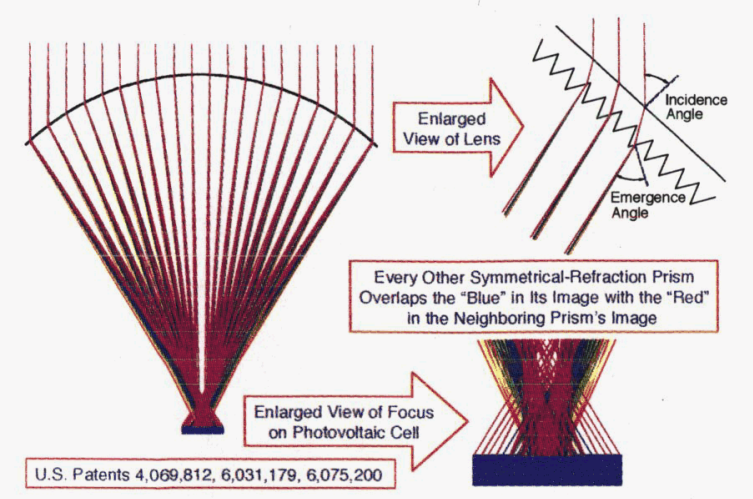

Fig 7. Symmetrical-Refraction Color-Mixing Fresnel Lens.

multitude of prisms in the symmetrical-refraction lens allows the individual prism angles to be tweaked to tailor the photon flux profile over the solar cell, both spatially and spectrally. For example, a patented optical innovation incorporated into the SCARLET and SLA lenses is an alternating-prism color-mixing feature that is critical to the optimal performance of monolithic multi-junction cells placed in the focus of such lenses [12].

Built and successfully tested in 2002, the rigid-panel SLA prototype wing in Fig. 5 included several complete photovoltaic receivers, each $0.5 \mathrm{~m}$ long and containing 14 series-connected triple-junction solar cells. The solar-to-electric conversion efficiency of each lens/receiver assembly was measured in a stateof-the-art solar simulator, using NASA Lear-Jetflown reference cells for calibration. The net aperture area efficiency of the best lens/receiver assembly was $27.5 \%$ under simulated space sunlight (AM0 spectrum) at $28^{\circ} \mathrm{C}$ cell temperature [13]. This net efficiency corresponds to $31 \%$ cell efficiency times $90 \%$ lens optical efficiency, and also matches separate NASA Lear Jet measurements on lens/cell units. On geostationary earth orbit (GEO), the operating cell temperature for SLA cells of this efficiency will be about $80^{\circ} \mathrm{C}$, resulting in a cell efficiency reduction factor of $87 \%$. Combining this factor with the geometrical packing loss factor (95\%), the net SLA efficiency at operating temperature on GEO at beginning of life (BOL) will be about $23 \%$, corresponding to a wing-level areal power density well above $300 \mathrm{~W} / \mathrm{m}^{2}$. At a $7 \mathrm{~kW}$ wing size, which is typical of current GEO communication satellites, the corresponding specific power is over $180 \mathrm{~W} / \mathrm{kg}(\mathrm{BOL})$ at operating temperature.

In addition, the well insulated photovoltaic receivers in the prototype SLA wing of Fig. 5 were wet hi-pot tested for possible leakage current with a $500 \mathrm{~V}$ potential applied between the cell circuits and the panel, and the measured leakage current was less than 1 micro-Amp for each receiver [13]. SLA's highvoltage capability is facilitated by photovoltaic cells, which allows super-encapsulation of the cell circuits at low mass penalty.

In addition to the near-term, low-risk rigid-panel version of SLA, an advanced version of SLA is also under development. The advanced version is a flexible-blanket SLA, similar to the small prototype array shown in Fig. 8. For this SLA version, the lenses form one flexible blanket while the radiator elements, containing the photovoltaic receivers, form a second flexible blanket. Both blankets fold up into a very compact stow volume for launch, and automatically deploy on orbit. One of the most efficient platforms for deploying and supporting the flexible-blanket version of SLA is the SquareRigger platform, developed by ABLE Engineering [14]. The SquareRigger platform was originally developed by ABLE under funding from the Air Force Research Laboratory for use with thin-film photovoltaic blankets in space. However, with the much higher efficiencies achievable with SLA compared to thinfilm photovoltaics, the marriage of SLA and SquareRigger provides unprecedented performance metrics, summarized in Table 1 [15].

Initial development of the SLA/SquareRigger technology, including a small prototype demonstrator (Fig. 9), has recently been completed by ABLE Engineering, with ENTECH subcontract support, under a NASA Small Business Innovation Research (SBIR) Phase I contract [14].

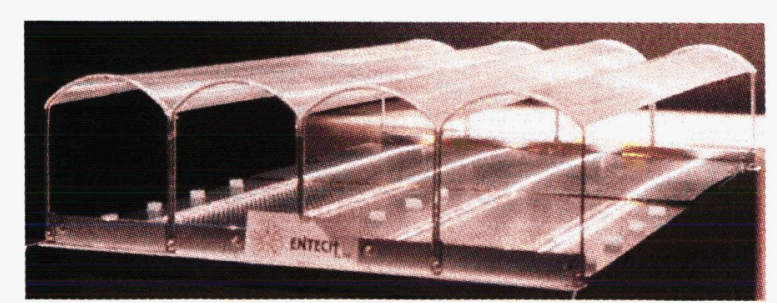

Fig. 8. Flexible-Blanket Stretched Lens Array (SLA) Prototype.

Table 1. Performance Attributes of SLA on ABLE's SquareRigger Platform.

\begin{tabular}{|l|c|c|}
\hline Time Frame & $<5$ Years & $5-10$ Years \\
\hline Power Capability $(\mathrm{kW})$ & 100 & 1,000 \\
\hline BOL Specific Power $(\mathrm{W} / \mathrm{kg})$ & 330 & 500 \\
\hline Stowed Power $\left(\mathrm{kW} / \mathrm{m}^{3}\right)$ & 80 & 120 \\
\hline Voltage & 1,000 & TBD \\
\hline
\end{tabular}




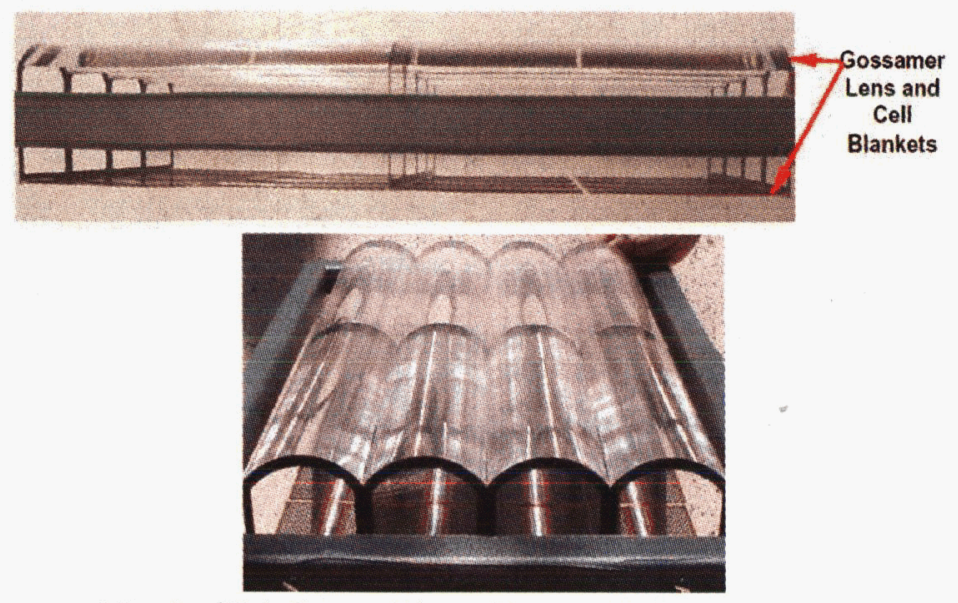

Fig. 9. SLA SquareRigger Prototype Demonstrator.

Additional development, including much larger scale hardware development, is currently being completed under a Phase II SBIR contract. All of this development work is directed toward the SLA/SquareRigger array approach shown schematically in Fig. 10. Analysis of this type of SLA/SquareRigger system led to the near-term and mid-term performance metric estimates of Table 1. Note that SLA/SquareRigger enables giant space solar arrays in the $100 \mathrm{~kW}$ to $1 \mathrm{MW}$ class, with spectacular performance metrics ( 300 to $500 \mathrm{~W} / \mathrm{kg}$ specific power, 80 to $120 \mathrm{~kW} / \mathrm{m}^{3}$ stowed power, and operational voltages above $1,000 \mathrm{~V}$ ) in the near-term (2010) to mid-term (2015).
In the longer term (2020-2025), with constantly improving solar cell efficiencies and incorporation of new nanotechnology materials into the lens and radiator elements, SLA's technology roadmap leads to $1,000 \mathrm{~W} / \mathrm{kg}$ solar arrays, as shown in Fig. 11 [16]. Indeed, SLA is unique among all solar array technologies in its portfolio of attributes, which include world-record-level solar-to-electric conversion efficiency (high $\mathrm{W} / \mathrm{m}^{2}$ ), ultra-light mass density $\left(\right.$ low $\left.\mathrm{kg} / \mathrm{m}^{2}\right)$, spectacular stowed power density $\left(\mathrm{kW} / \mathrm{m}^{3}\right)$, highly scalable power ( $\mathrm{kW}$ to multi-MW), high-voltage capability $(\mathrm{kV})$, modularity (individual lens/cell building blocks), massproducibility, and cost effectiveness.

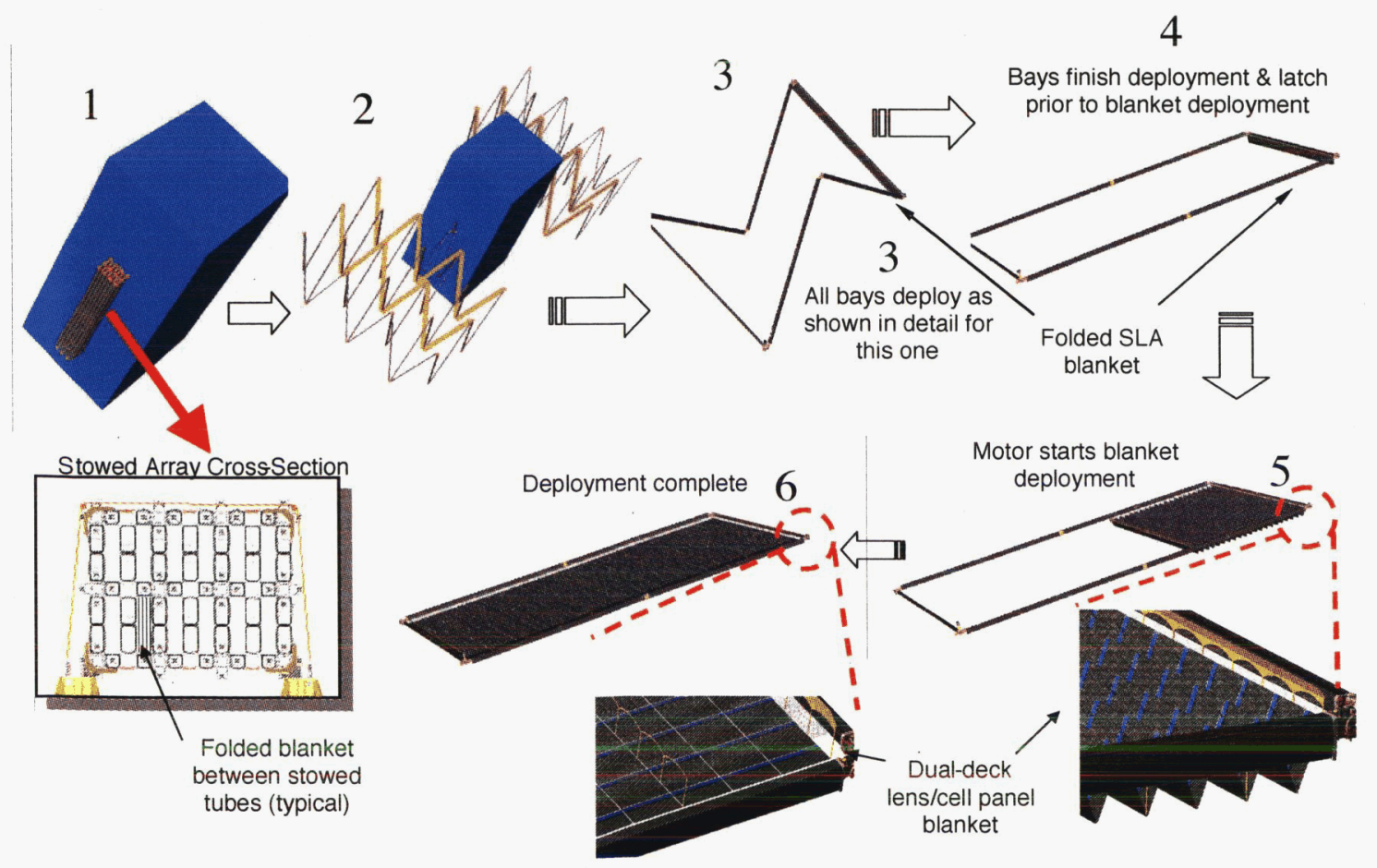

Fig. 10. Stretched Lens Array (SLA) on SquareRigger Platform. 


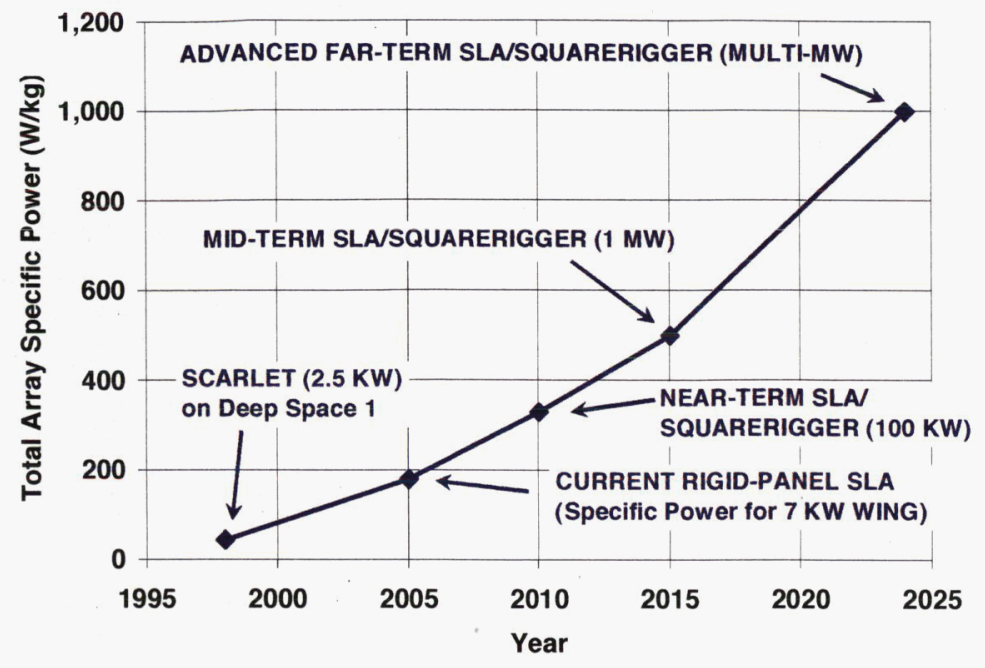

Fig. 11. Long-Term Technology Roadmap for the Stretched Lens Array (SLA).

SLA's unique portfolio of attributes matches the critical requirements for space power systems for many of planned NASA's Exploration missions.

\section{TECHNICAL PROGRESS}

The combination of SLA technology with SEP technology offers spectacular economic payoffs for transporting cargo from the Earth to the Moon to support robotic and human exploration missions. However, several critical questions must be answered before this potential can be realized, including:

- Can the SLA (or any solar array for that matter) operate reliably over many years at $600 \mathrm{~V}$ in the harsh space environment?

- Can the SLA lens survive many years in the harsh space environment, especially the highradiation environment involved in multiple slow transits of the radiation belts?

- Can the SLA and the electric thrusters operate together, in a direct-drive mode, efficiently and reliably over many years in the harsh space environment?

Limited efforts are being made to answer some of the concerns such as coupon testing in environmental chambers, component testing at high voltage, etc.

To operate reliably for many years at high voltage, the photovoltaic cell circuit must be extremely well insulated, to prevent electrical interaction with the space plasma or with the "grounded" solar array structures. Figure 12 shows a fully encapsulated photovoltaic receiver sample for a $600 \mathrm{~V}$ version of
SLASR for such an SEP mission [14]. This test sample has been subjected to underwater hi-pot tests with more than 2,200 V bias applied between the solar cell and the composite radiator, which was surrounded by water to crudely simulate space plasma. The leakage current was less than 1 microamp, indicating the excellent resistance for the encapsulation above and below the cell. The top surface of the cell can be encapsulated with either a thin cover glass or with a silicone prismatic cell cover. The thickness of either type of cell cover is optimized by trading off radiation degradation and array mass for the specific mission.

Another on-going test of the fully encapsulated highvoltage photovoltaic receiver circuits used in SLA is shown during installation in Fig. 13. An ENTECH terrestrial solar concentrator array, called a SunLine, was equipped by Boeing with high-voltage multijunction solar cells under a NASA-sponsored program in 2003 [17]. This array was tested on Mount Haleakala for six months in 2003, and has recently been relocated to ENTECH for additional

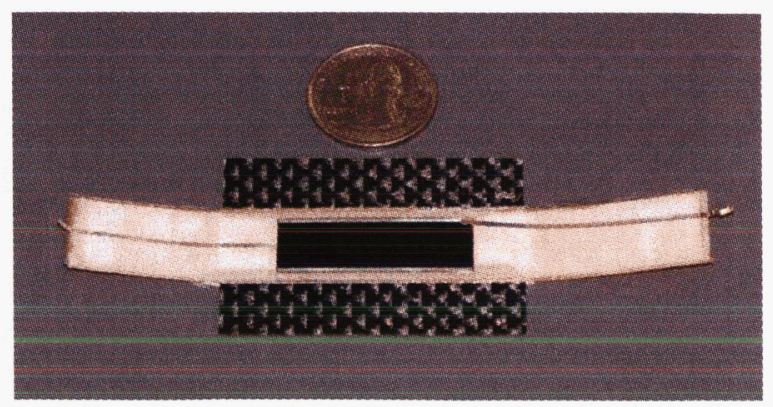

Fig. 12. Fully Encapsulated SLASR Receiver Sample. 


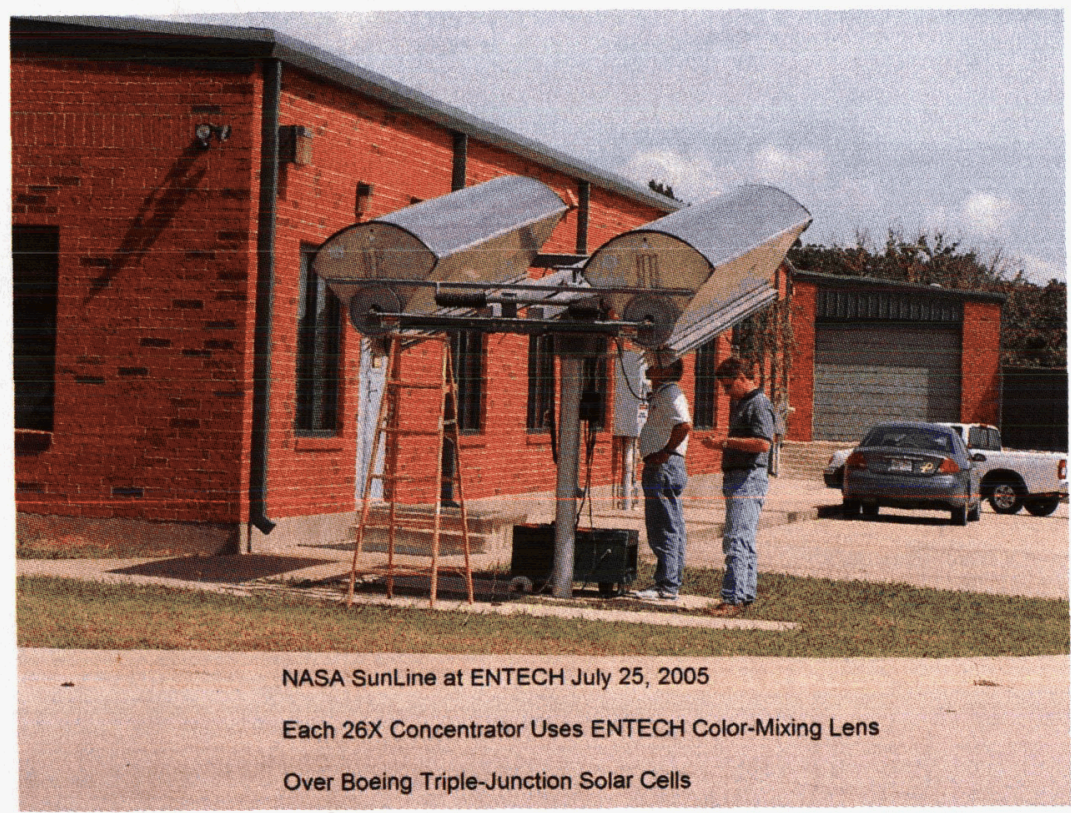

Fig. 13. Relocation of $1 \mathrm{~kW}$ SunLine Array with 600-Volt Photovoltaic Receiver Circuits from Hawaii to ENTECH.

testing. The array provides over $1 \mathrm{~kW}$ of output power under clear sky conditions, and has an opencircuit voltage of approximately $600 \mathrm{~V}$ under typical outdoor conditions. The photovoltaic circuits in this array include many of the features of the planned circuits for SLA high-voltage arrays for SEP missions in space. ENTECH is operating this array continuously at open-circuit conditions to evaluate the long-term reliability of these planned SLA photovoltaic circuits. To date, the array has performed very well under the constantly varying solar irradiance and ambient temperature conditions for an air-cooled outdoor solar array.

Much additional technology development and maturation work is ongoing for the SLA, in areas ranging from radiation-hardening coatings for the lens to advanced cell development, as discussed in more detail in another paper at this conference [18]. Efforts to date indicate that the SLA should indeed be capable of efficient and reliable operation for reusable SEP space tugs delivering substantial amounts of cargo from LEO to lunar orbit.

\section{CONCLUSIONS}

- Solar electric propulsion using direct-drive high-voltage high-performance solar arrays offers substantial benefits for delivering cargo in support of exploration missions to the Moon, and later to Mars.
- One $600 \mathrm{~kW}$ reusable space tug can save over $\$ 3$ billion in launch costs alone in delivering 110 metric tons of cargo to the Moon.

- The critical enabling technology for such SEP space tug missions is the highperformance, ultra-light, radiation-durable, scalable, cost-effective, high-voltage solar array.

- The Stretched Lens Array (SLA) offers the portfolio of attributes and performance metrics needed for SEP space tug missions.

- Ground tests and later flight tests are critical to validate the SLA technology for directdrive SEP missions.

- Initial ground tests are underway and additional ground tests are planned for the next 2-3 years to support the development of SLA for direct-drive SEP missions.

\section{ACKNOWLEDGMENTS}

An excellent team of industry, university, and government organizations has been developing the Stretched Lens Array and SEP technologies, supported by a number of NASA contracts. The authors are grateful for the contributions of these team members and the financial support by NASA. 


\section{REFERENCES}

1. Hamley, J.A., et al., "Hall Thruster Direct Drive Demonstration," 33rd AIAA/ASME/SAE/ASEE Joint Propulsion Conference, Seattle, 1997.

2. Hoskins, W.A., et al., "Direct Drive Hall Thruster System Development," 39th AIAA/ASME/SAE/ASEE Joint Propulsion Conference, Huntsville, 2003.

3. Hoeber, C.F., et al., "Solar Array Augmented Electrostatic Discharge in GEO," 17th International Communication Satellite System Conference, Yokohama, 1998.

4. Katz, I. and Snyder, D.B., "Mechanism for Spacecraft Charging Initiated Destruction of Solar Arrays in GEO," 36th Aerospace Sciences Meeting, Reno, 1998.

5. Piszczor, M.F. and O’Neill, M.J., "Development of a Dome Fresnel Lens/GaAs Photovoltaic Concentrator for Space Applications," 19th IEEE Photovoltaic Specialists Conference (PVSC), New Orleans, 1987.

6. O'Neill, M.J., "Silicon Low-Concentration, LineFocus, Terrestrial Modules," Chapter 10 in Solar Cells and Their Applications, John Wiley \& Sons, New York, 1995.

7. Curtis, H. and Marvin, D., "Final Results from the PASP Plus Flight Experiment," 25th IEEE PVSC, Washington, 1996.

8. Jones, P.A., et al., "The SCARLET Light Concentrating Solar Array," 25th IEEE PVSC, Washington, 1996.

9. Murphy, D.M., "The SCARLET Solar Array: Technology Validation and Flight Results," Deep Space 1 Technology Validation Symposium, Pasadena, 2000.

10. O'Neill, M.J., et al., "Development of the UltraLight Stretched Lens Array," 29th IEEE PVSC, New Orleans, 2002.

11. O'Neill, M.J., "Stretched Fresnel Lens Solar Concentrator for Space Power," U.S. Patent $6,075,200,2000$.

12. O'Neill, M.J., "Color-Mixing Lens for Solar Concentrator System and Methods of Manufacture and Operation Thereof," U.S. Patent 6,031,179, 2000.

13. Piszczor, M.F., et al., "Stretched Lens Array (SLA) Photovoltaic Concentrator Hardware Development \& Testing," Third World Conference on Photovoltaic Energy Conversion, Osaka, 2003.

14. Eskenazi, M., et al., "Promising Results from Three SBIR Solar Array Technology Development Programs," 18th Space Photovoltaic Research and Technology (SPRAT)
Conference, Cleveland, 2003.

15. O'Neill, M.J., et al., "Recent Progress on the Stretched Lens Array (SLA)," 18th Space Photovoltaic Research and Technology (SPRAT) Conference, Cleveland, 2003.

16. O'Neill, M.J., " $1,000 \mathrm{~W} / \mathrm{kg}$ Solar Concentrator Arrays for Far-Term Space Missions, Space Technology \& Applications International Forum (STAIF 2004), Albuquerque, 2004.

17. Mehdi, I.S. et al, "High Voltage Solar Concentrator Experiment with Implications for Future Space Missions," Solar Power from Space (SPS04) and 5th Wireless Power Transmission (WPT5) Conference, Granada, Spain, 2004.

18. O'Neill, M.J., et al., "Stretched Lens Array SquareRigger (SLASR): A Unique High-Power Solar Array For Exploration Missions," 56th IAC, Fukuoka, Japan, 2005. 

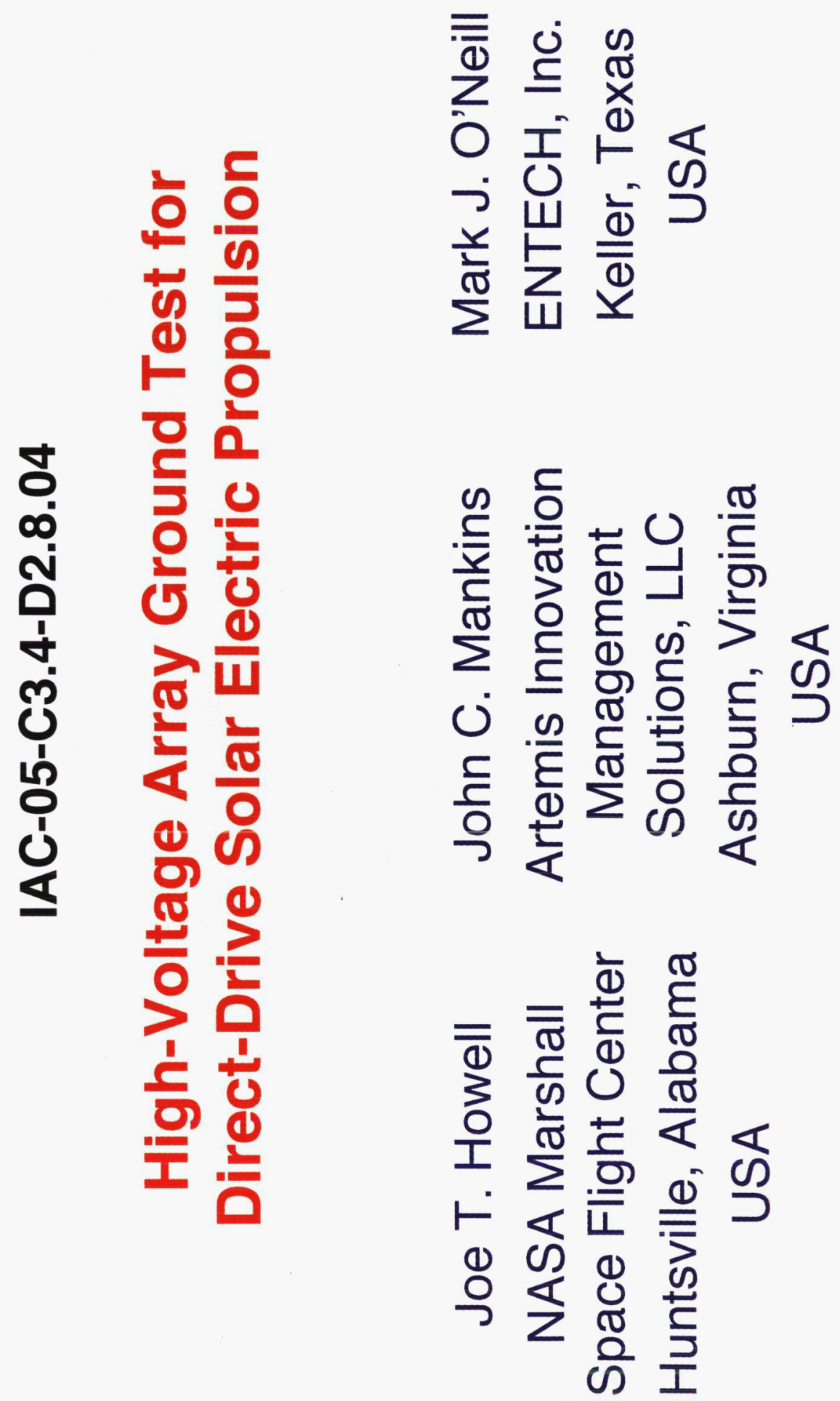


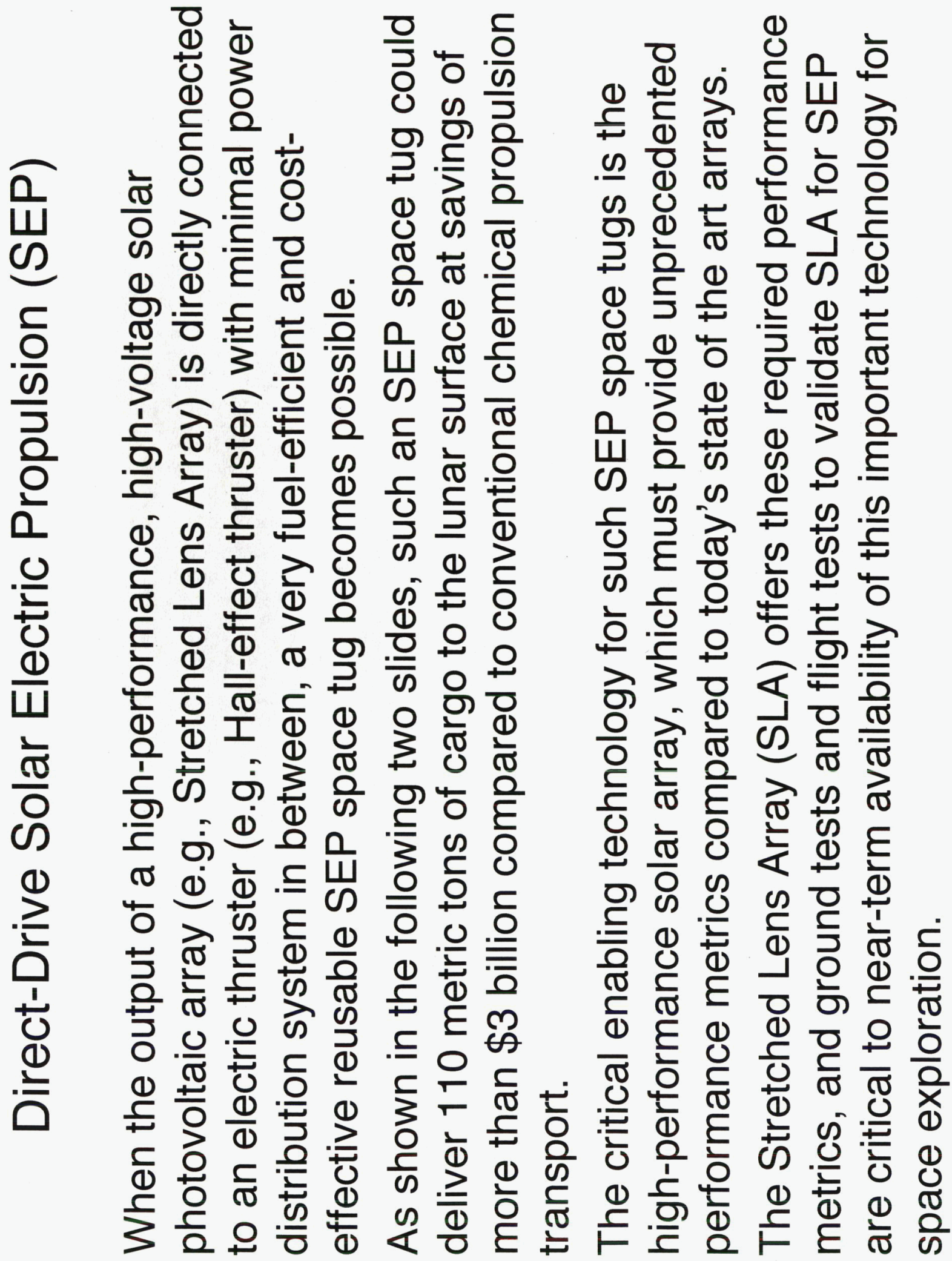




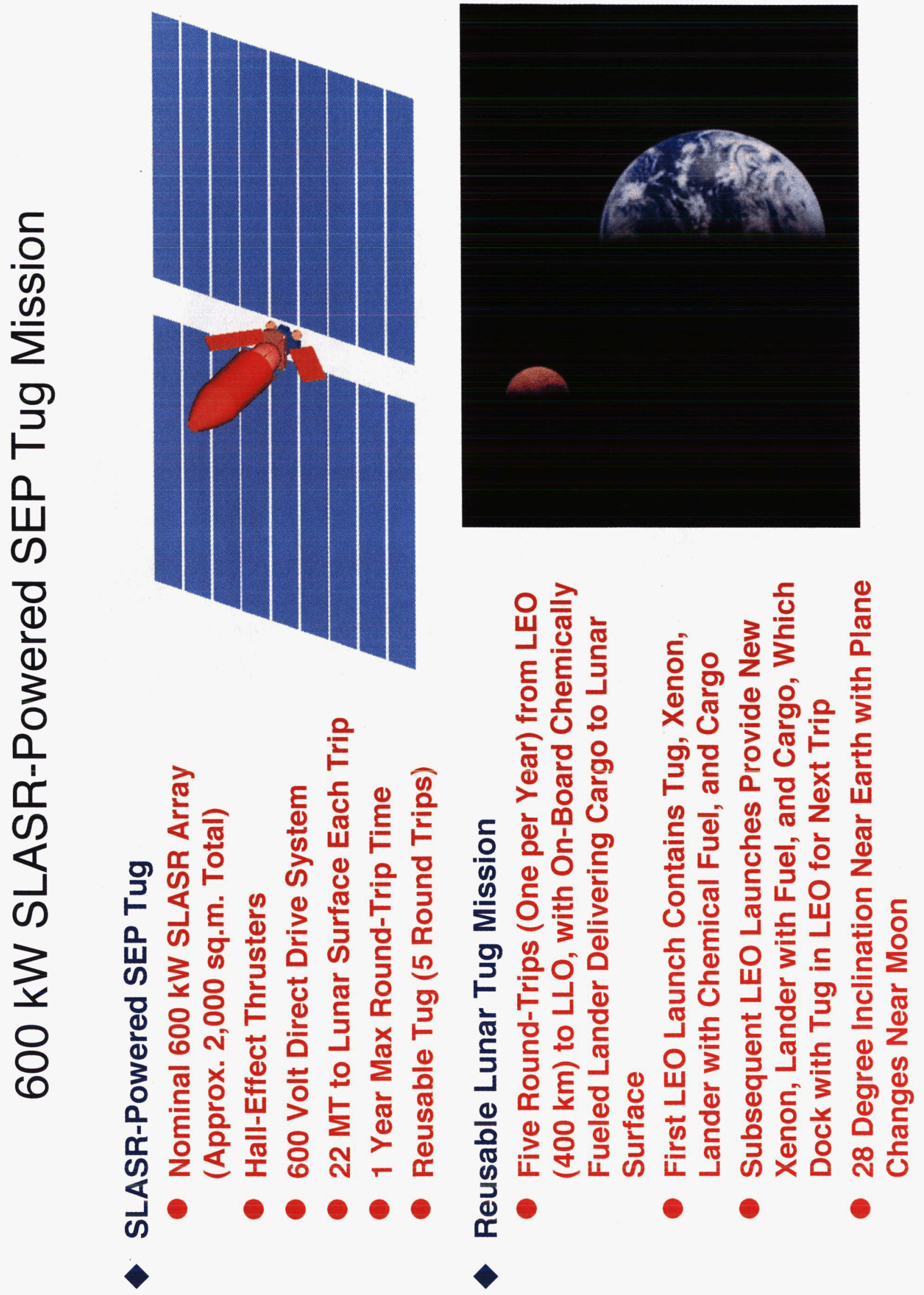


๙

(1)

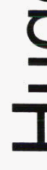

$\frac{0}{0}$

岂

$\stackrel{\text { ฮั }}{5}$

7

(1)

(1)

$\sum_{0}$

0

व́

$\infty$

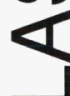

๘

文
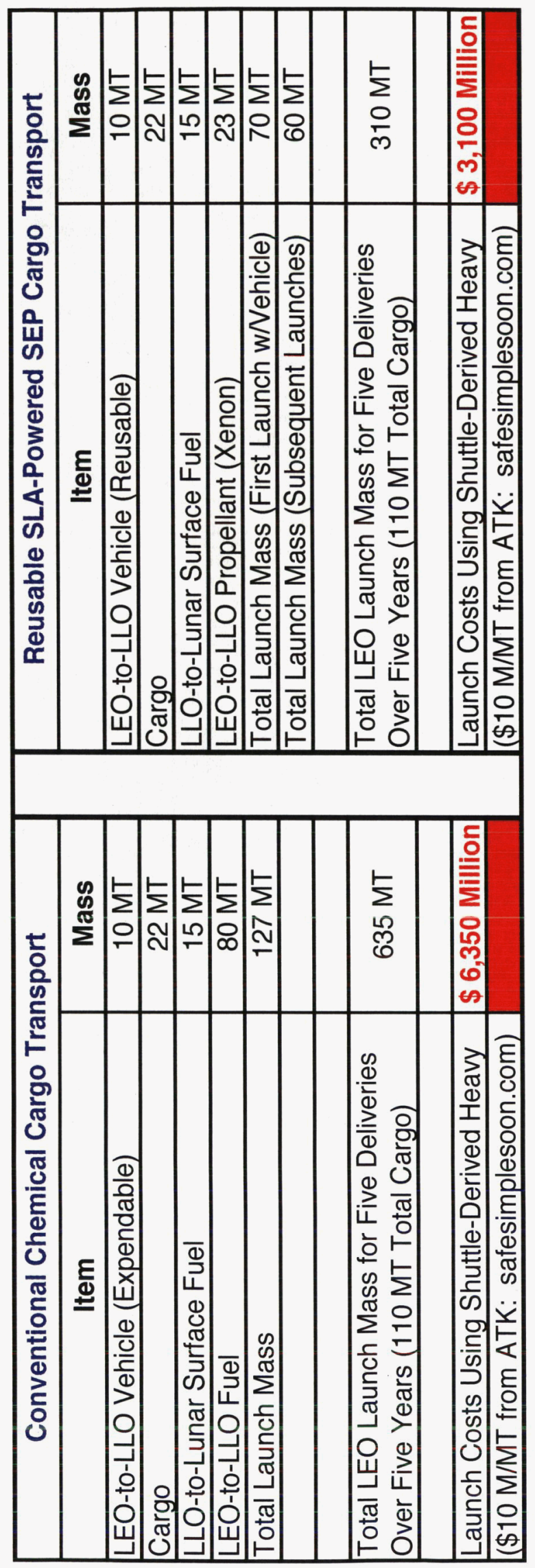

$\varphi$

일 들 $\frac{1}{0} \geqslant$

$F>\sum_{0}^{2}$ 닫

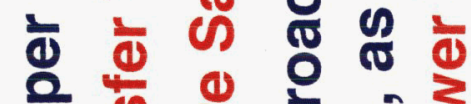

2 운 은

들 응 히

क 즌 $\sum$ 원 $\frac{1}{6}$

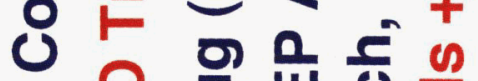

다이

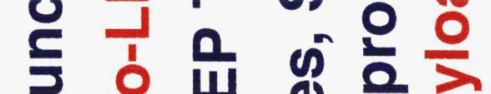

하

10 의 은

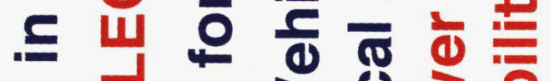

두응

के एक ह ब

$3 \stackrel{0}{3}$ 은 능

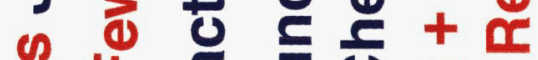

ㄴㄴ 진

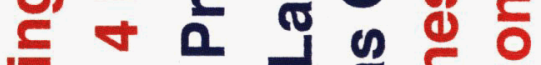

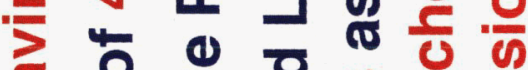

ल

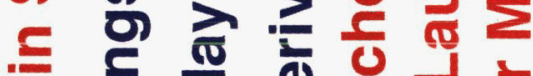

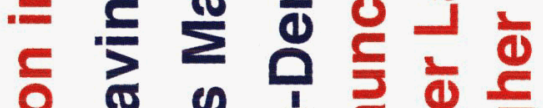

-

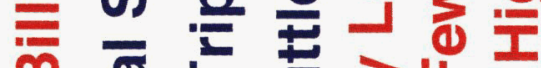

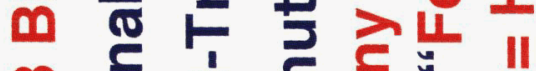

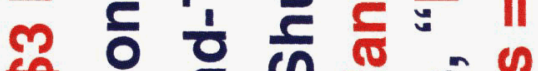

क 을

히흥 응

$>$ 웅 옹

0 \& 0 元

히 든

* 4 둔 0

00 은 은

0 015

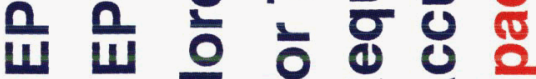

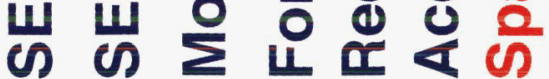



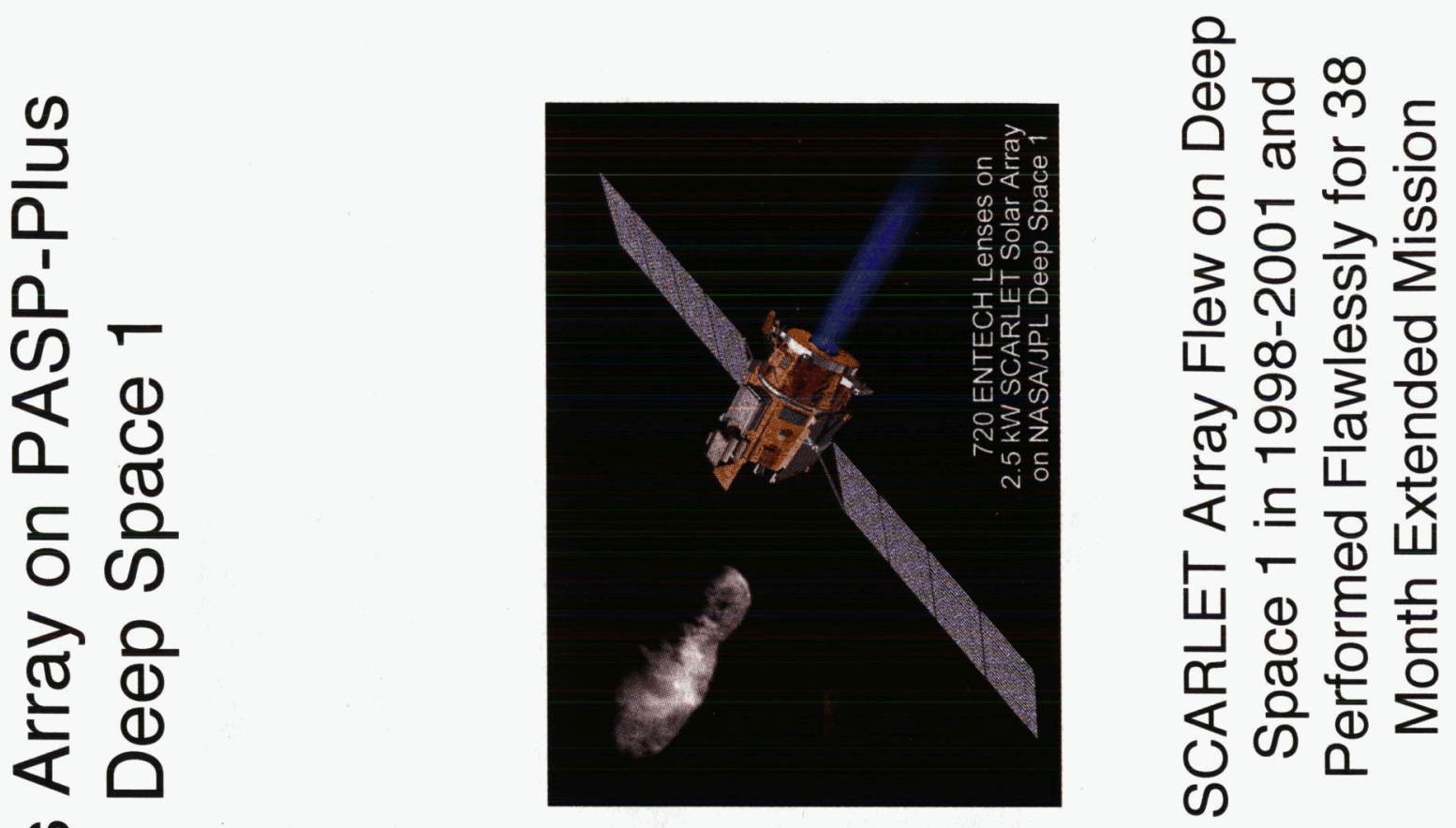

e $\frac{E}{0}$

(1) 눌

$\sum_{-\frac{1}{2}}$

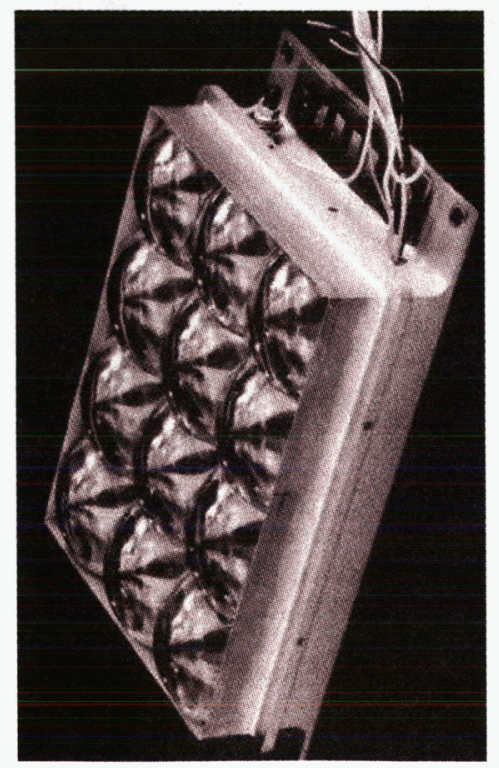

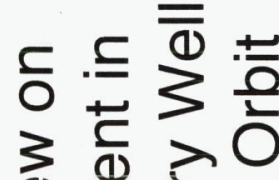

(1) है ฮ ত

느히 응

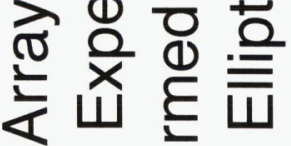

$\therefore 0$

음

D)

0

D

ก

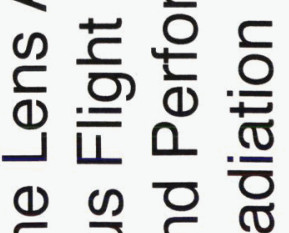

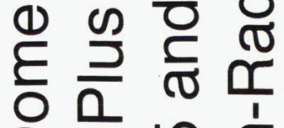

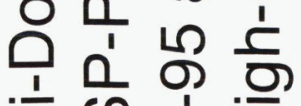

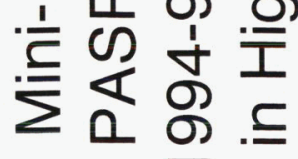




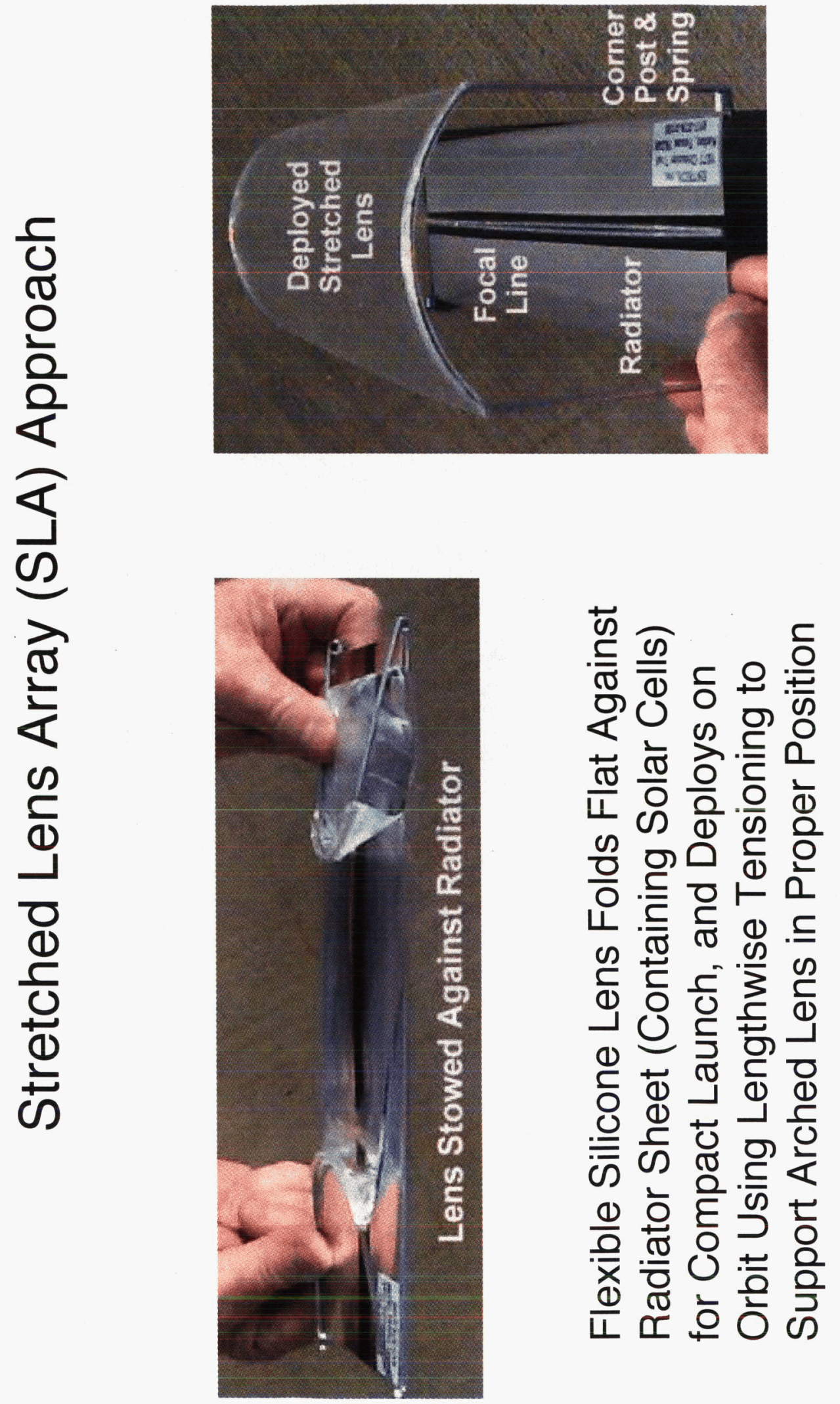



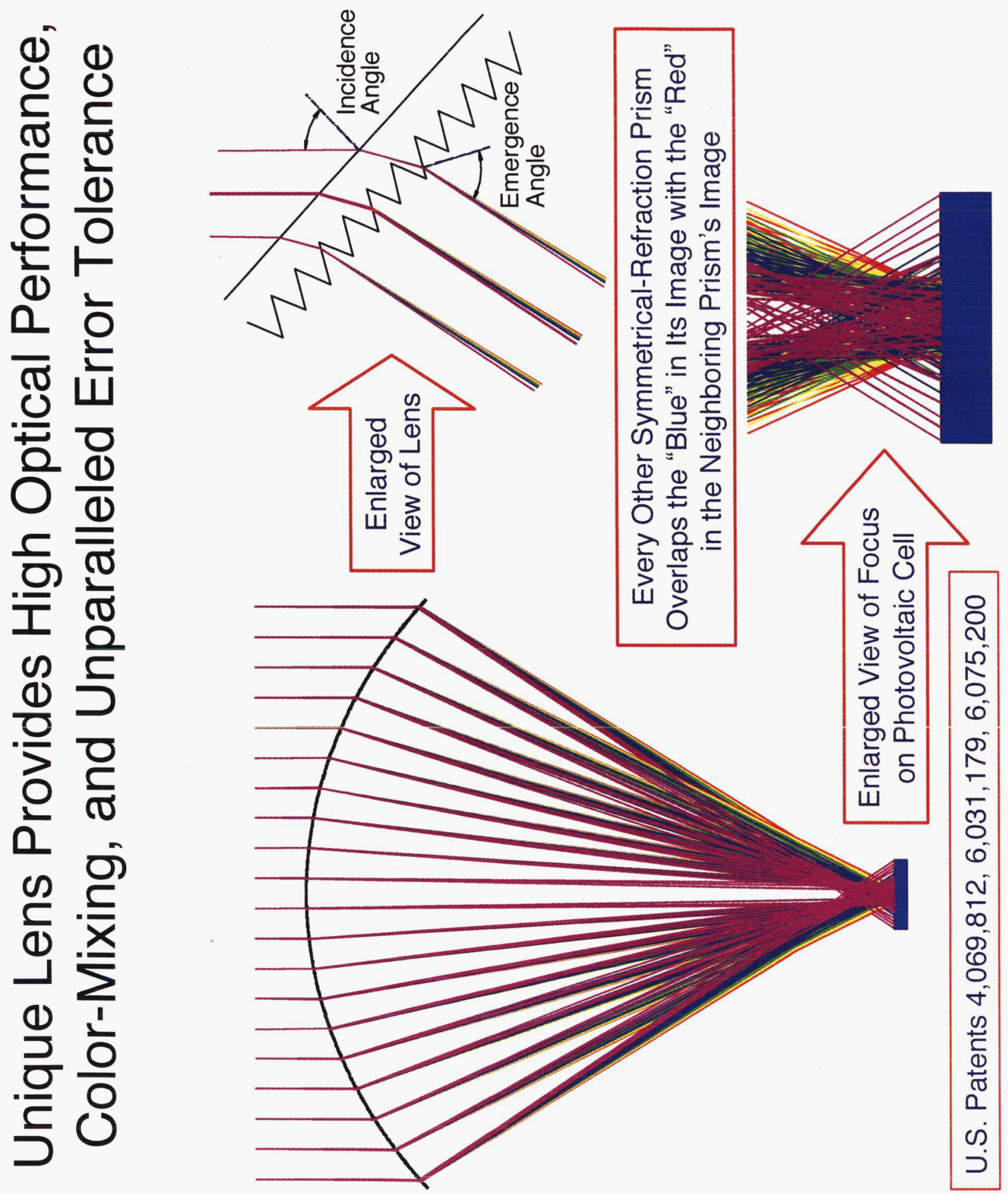

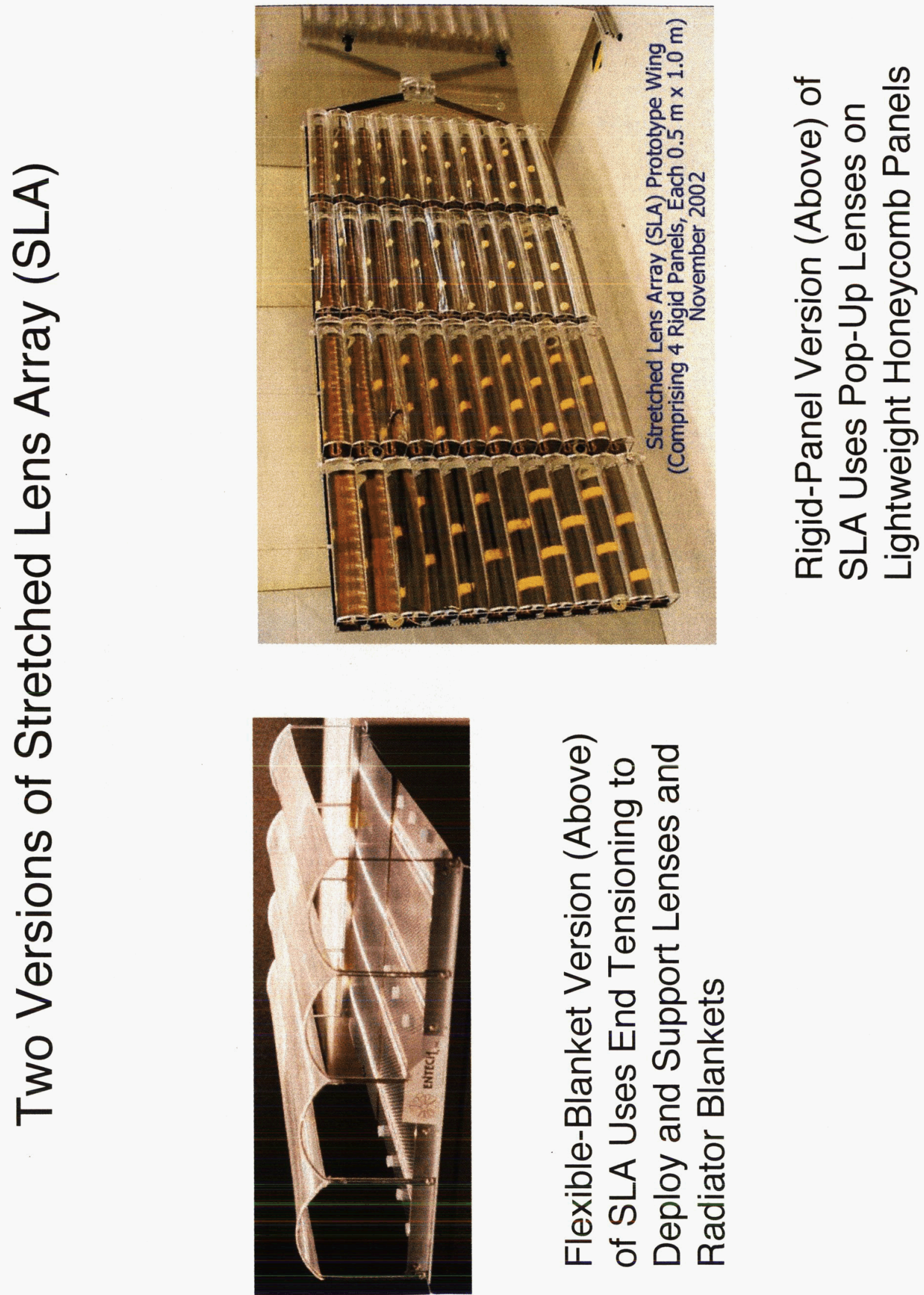


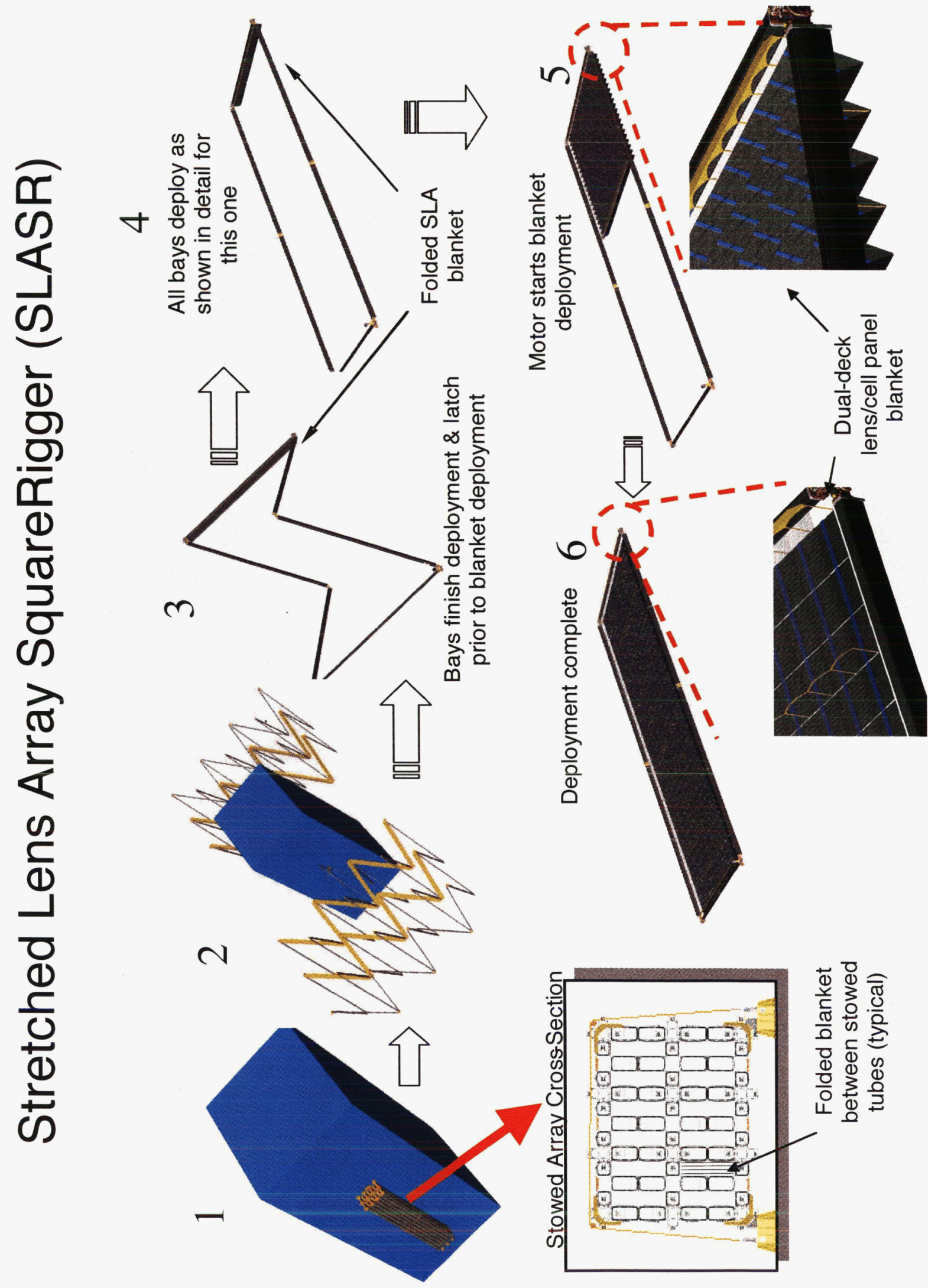



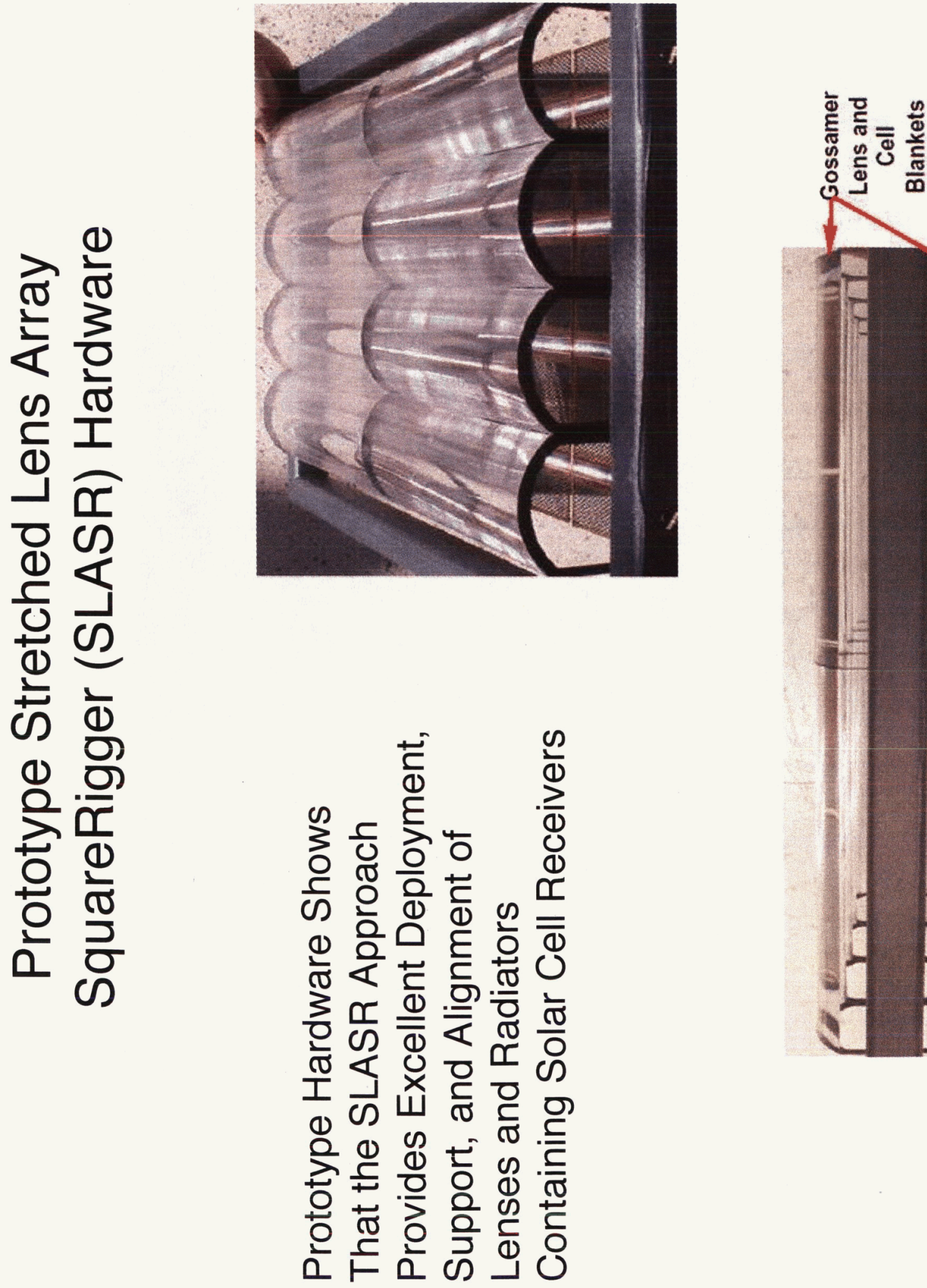

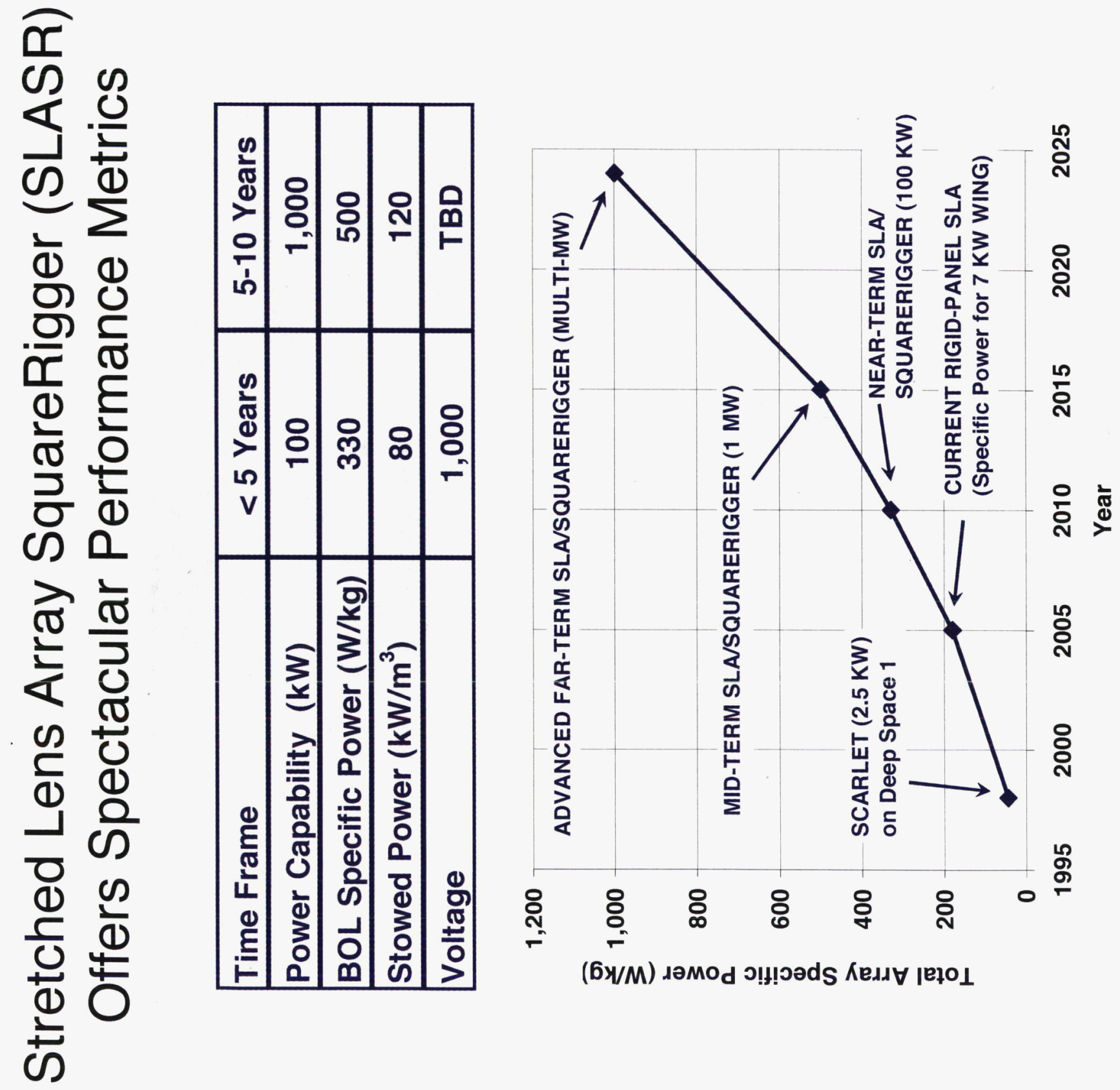

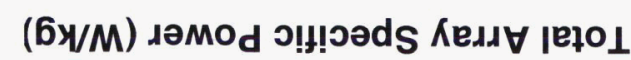



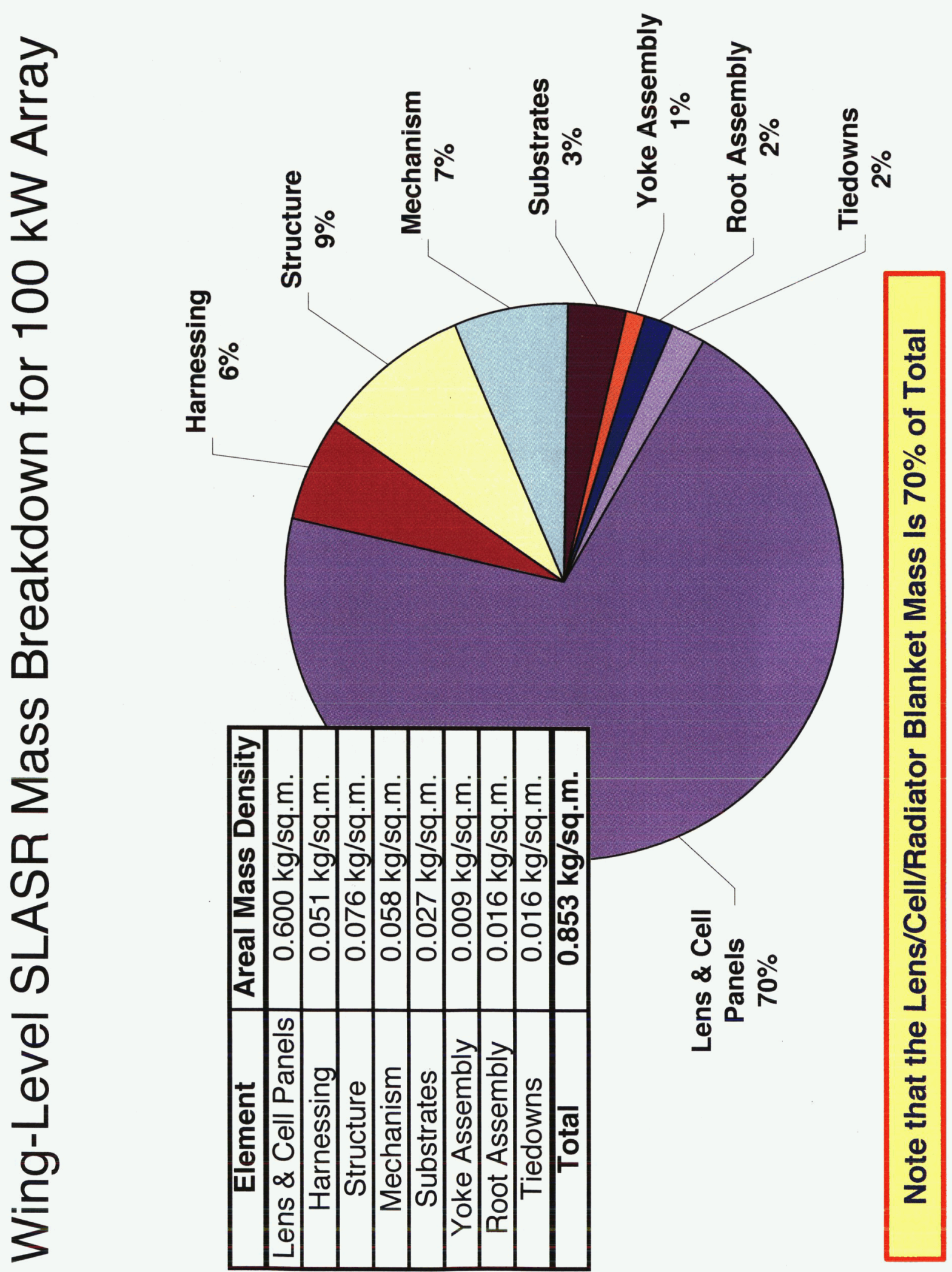


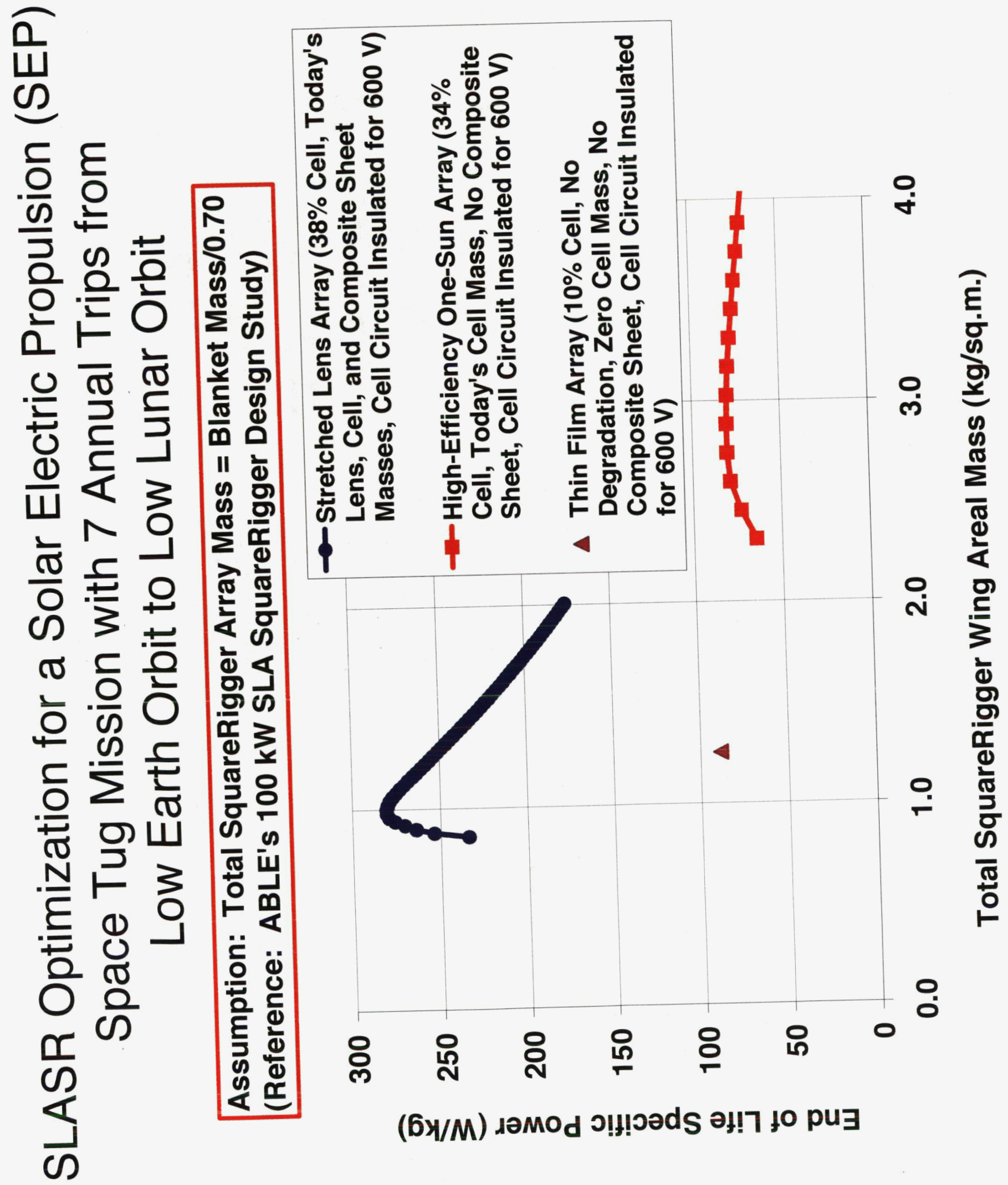


을

ஸ

(1)

2

(1)

8

$\Phi$

(口)

4

$\overrightarrow{0}$

7

$\Phi$

(1)

$\frac{7}{5}$

ด

음

일

U

픈

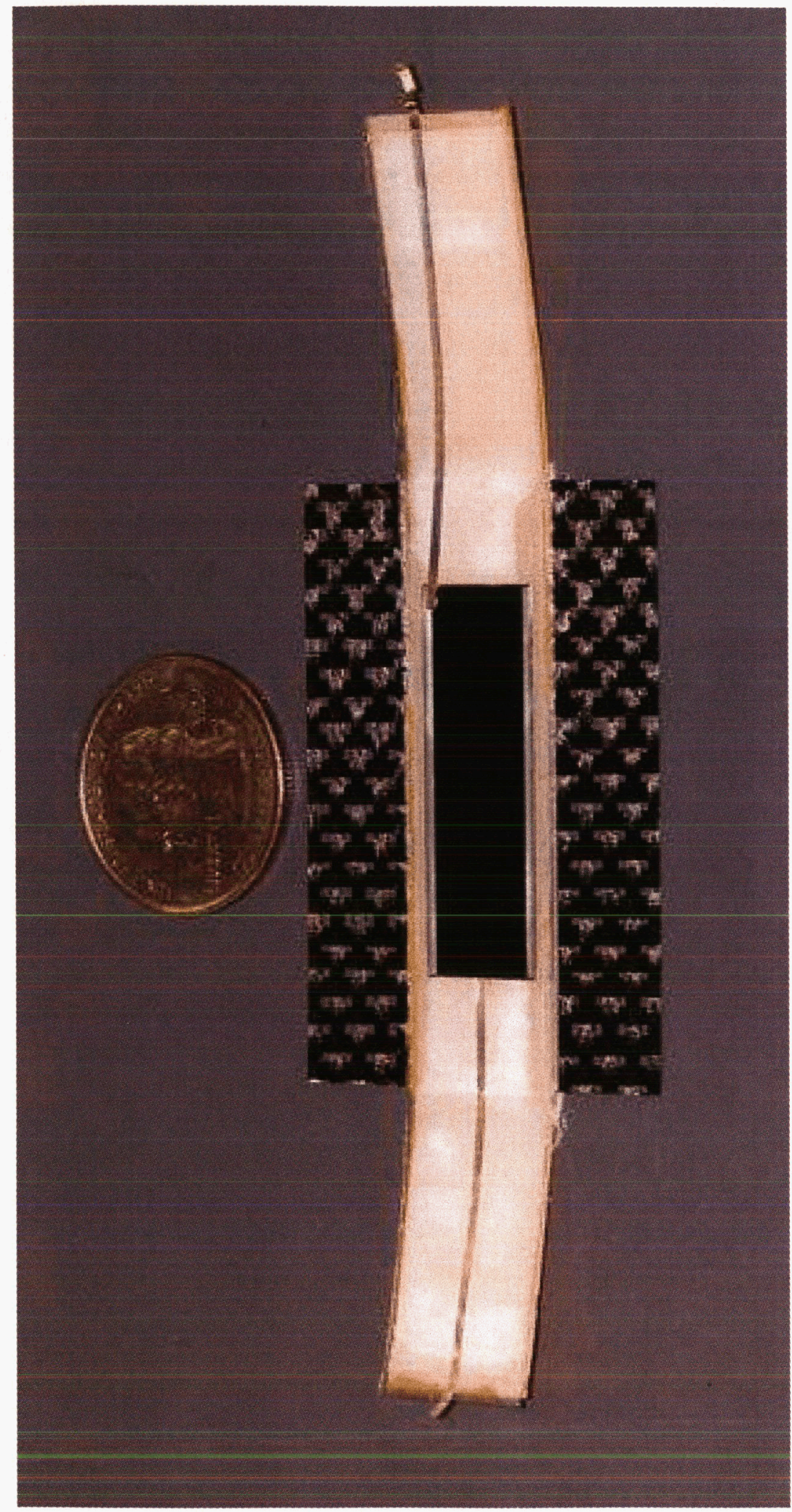




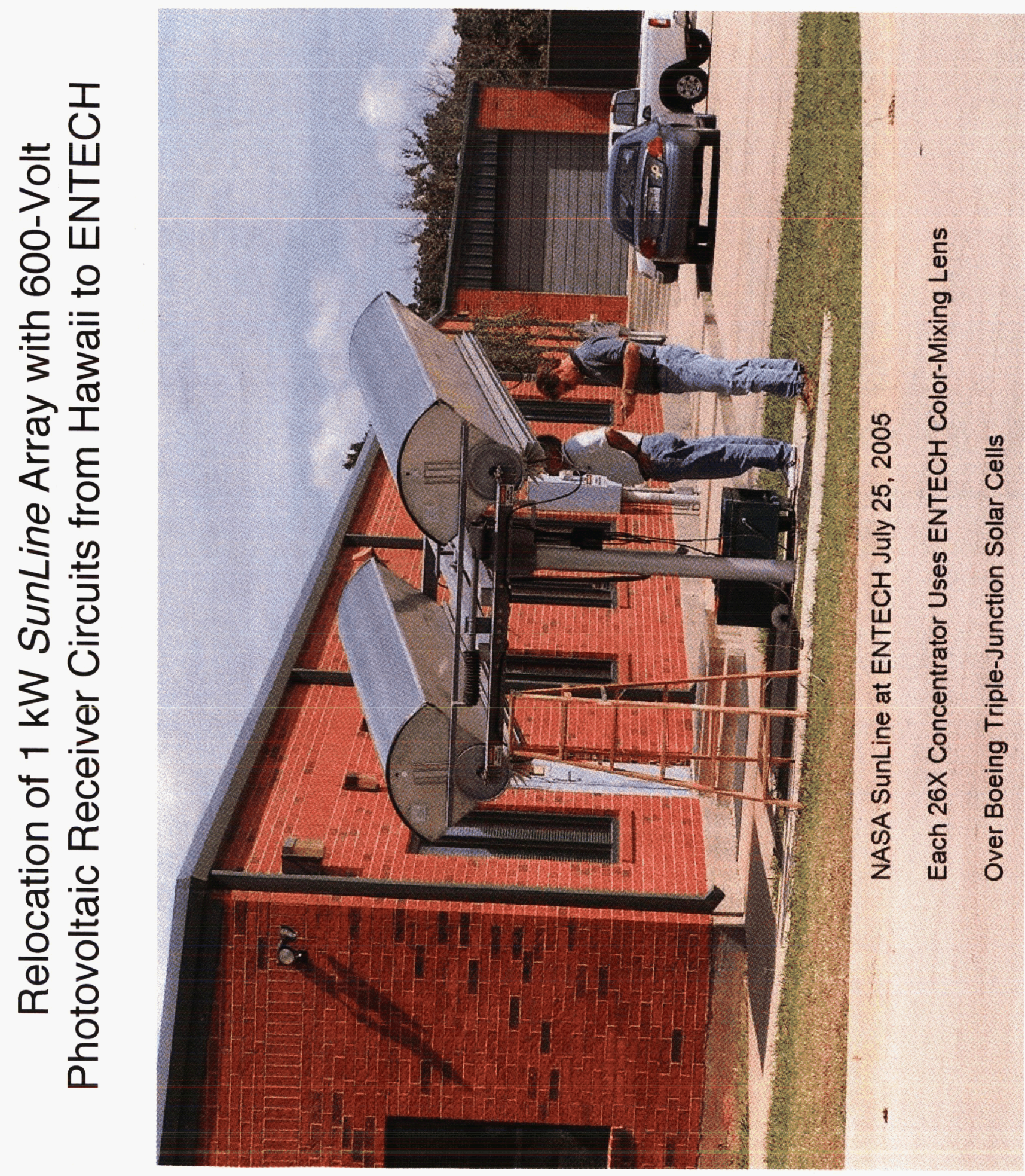




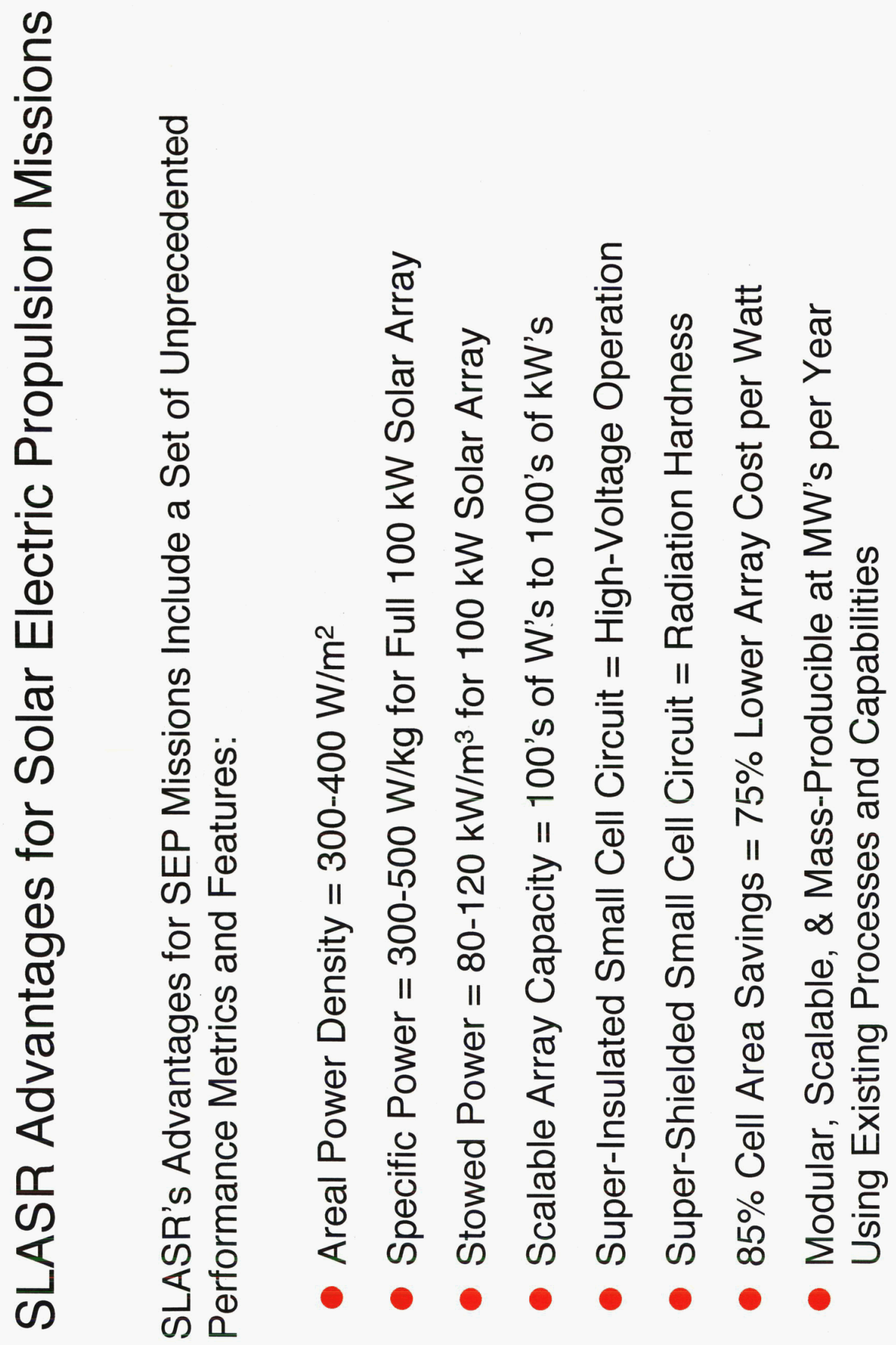




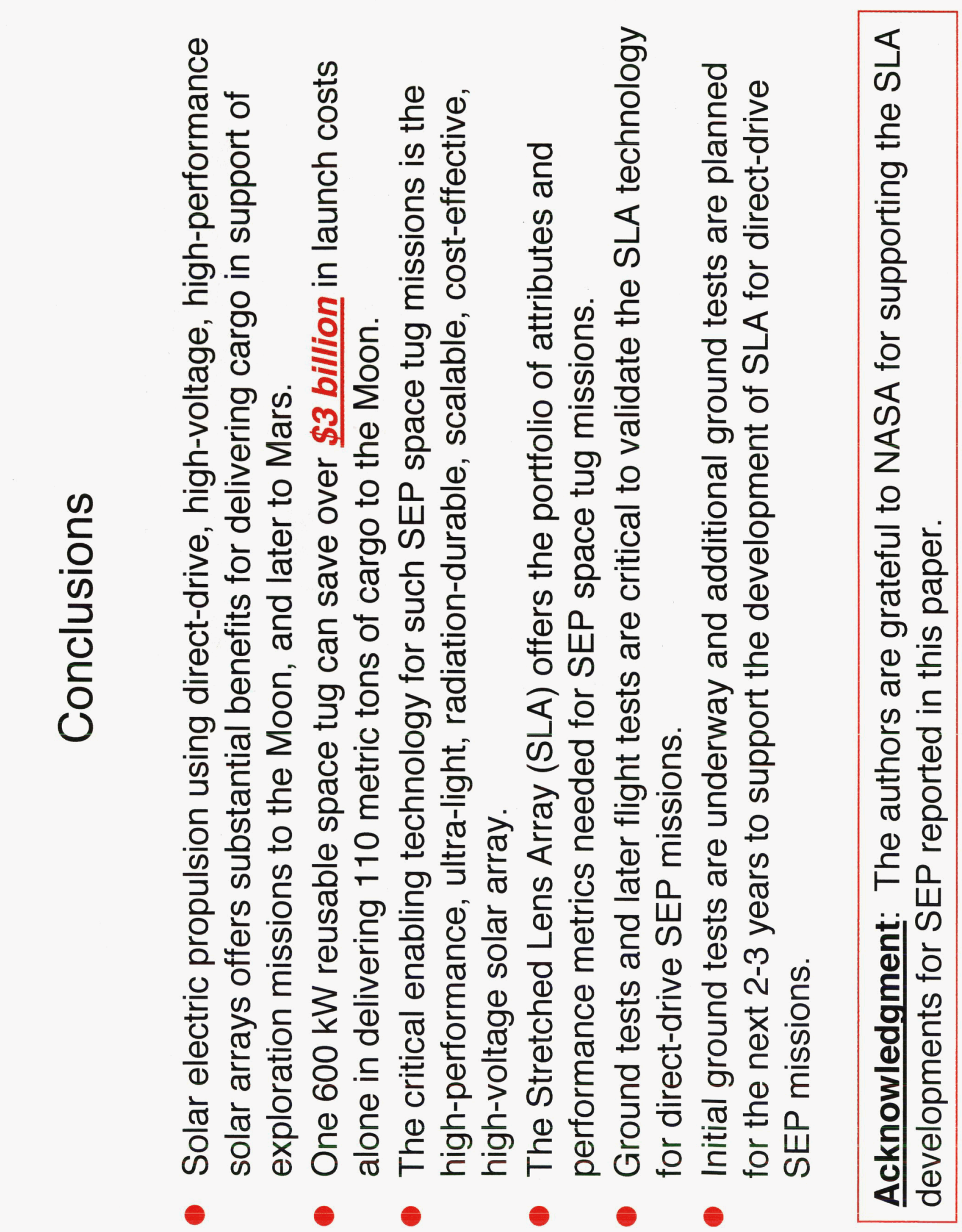

